\title{
Review Article \\ Therapeutic Implications of Targeting AKT Signaling in Melanoma
}

\author{
SubbaRao V. Madhunapantula ${ }^{1,2}$ and Gavin P. Robertson ${ }^{1,2,3,4,5,6}$ \\ ${ }^{1}$ Department of Pharmacology, The Pennsylvania State University College of Medicine, Hershey, PA 17033, USA \\ ${ }^{2}$ Penn State Melanoma Center, The Pennsylvania State University College of Medicine, Hershey, PA 17033, USA \\ ${ }^{3}$ Department of Pathology, The Pennsylvania State University College of Medicine, Hershey, PA 17033, USA \\ ${ }^{4}$ Department of Dermatology, The Pennsylvania State University College of Medicine, Hershey, PA 17033, USA \\ ${ }^{5}$ Penn State Melanoma Therapeutics Program, The Pennsylvania State University College of Medicine, Hershey, PA 17033, USA \\ ${ }^{6}$ The Foreman Foundation for Melanoma Research, The Pennsylvania State University College of Medicine, Hershey, PA 17033, USA
}

Correspondence should be addressed to Gavin P. Robertson, gprobertson@psu.edu

Received 26 October 2010; Accepted 1 January 2011

Academic Editor: Yong-Doo Park

Copyright ( $) 2011$ S. V. Madhunapantula and G. P. Robertson. This is an open access article distributed under the Creative Commons Attribution License, which permits unrestricted use, distribution, and reproduction in any medium, provided the original work is properly cited.

\begin{abstract}
Identification of key enzymes regulating melanoma progression and drug resistance has the potential to lead to the development of novel, more effective targeted agents for inhibiting this deadly form of skin cancer. The Akt3, also known as protein kinase B gamma, pathway enzymes regulate diverse cellular processes including proliferation, survival, and invasion thereby promoting the development of melanoma. Accumulating preclinical evidence demonstrates that therapeutic agents targeting these kinases alone or in combination with other pathway members could be effective for the long-term treatment of advanced-stage disease. However, currently, no selective and effective therapeutic agent targeting these kinases has been identified for clinical use. This paper provides an overview of the key enzymes of the PI3K pathway with emphasis placed on Akt3 and the negative regulator of this kinase called PTEN (phosphatase and tensin homolog deleted on chromosome 10). Mechanisms regulating these enzymes, their substrates and therapeutic implications of targeting these proteins to treat melanoma are also discussed. Finally, key issues that remain to be answered and future directions for interested researchers pertaining to this signaling cascade are highlighted.
\end{abstract}

\section{Introduction}

Kinases and phosphatases are the key components of signaling cascades regulating metabolic processes such as cell survival, proliferation, apoptosis, differentiation, and cell motility [1-4]. Aberrant expression and activities of these enzymes have been reported to lead to the development of several cancers including melanoma [4-10]. Due to genetic and epigenetic modifications, deregulating oncogenic kinases and tumor inhibitory proteins, melanocytes acquire transformed characteristics leading to malignant melanoma [4-10]. Members of the PI3K and Akt3 signaling cascades have been implicated in initiation, progression, invasive, and drug resistance phenotypes of melanomas [1-4]. Enzymes in this signaling cascade are therefore attractive targets for treating or preventing melanoma development [11-13]. This paper provides an overview of enzymes involved in PI3KAkt signaling pathway focusing specifically on the tumor suppressor phosphatase PTEN, lipid kinase PI3K, and the oncogenic survival kinase Akt3. Key structural features, mechanisms regulating the expressionm and activities of these proteins as well as therapeutic implications of targeting this pathway to treat melanoma are reviewed.

1.1. Tumor Suppressor PTEN Is a Key Phosphatase Regulating PI3K-Akt3 Signaling and Thereby Melanoma Development. The PTEN (phosphatase and tensin homolog deleted on chromosome 10) gene, which is also known as MMAC1 (mutated in multiple advanced cancers), and TEP1 (TGF- $\beta$ regulated and epithelial cell-enriched phosphatase) is a unique $55 \mathrm{kDa}$ dual specificity phosphatase located on 
the long arm of chromosome 10 at $10 \mathrm{q} 23[14,15]$. PTEN dephosphorylates proteins [16-18] and hydrolyzes the secondary messenger inositol trisphosphates $\left(\mathrm{PIP}_{3} \mathrm{~s}\right)[17$, 19] thereby inhibiting the activities of several proteins or pathways, which regulate cell proliferation, survival, and apoptosis $[14,20]$.

Preclinical and clinical evidence has demonstrated the inactivation of PTEN in 29 to $43 \%$ of melanoma cell lines or tumors from patients. For example, a recent study showed decreased PTEN expression in $43 \%$ melanoma cases and demonstrated a significant correlation between alterations in PTEN expression and primary tumor ulceration [20]. However, only a few studies, although controversial, demonstrated the clinical implications of PTEN as a prognostic marker in melanoma. Addressing this aspect, a recent study concluded that the utility of PTEN status as a prognostic marker is limited despite decreased PTEN expression observed commonly in primary melanomas associated with aggressive tumor behavior [20]. This clinical study analyzed 127 primary melanomas and found no significant association between PTEN expression and patient survival.

Key experiments demonstrating the tumor suppressor function of PTEN in melanomas include (a) triggering and sensitization of melanoma cells to apoptosis following introduction of PTEN (Figure 1) $[8,22]$ as demonstrated by increased cleaved caspase- 3 only when wild-type PTEN is expressed compared to inactive G129R mutant in UACC 903 cells [8]; (b) enhanced phosphorylation of Akt3 in melanocytes and early melanoma WM35 cells expressing wild-type PTEN protein only upon PTEN inhibition [23]; (c) loss of cell viability, decreased activity of Akt3, and downstream pPRAS40 following the introduction of PTEN in melanoma cells lacking functional protein (Figure 2) [8, 9, 21]; (d) appearance of spontaneous melanoma tumors in mice lacking PTEN ${ }^{-/-}$and expressing conditionally induced ${ }^{\mathrm{V} 600 \mathrm{E}} \mathrm{B}-\mathrm{Raf}$. B-Raf, one of the key regulators of proliferation, has been shown to be mutated in $\sim 60 \%$ melanomas $[4$, 24]. The most common mutation T1799A, which results in the substitution of valine to glutamic acid, has been identified in $>90 \%$ of melanoma patient tumors harboring a mutant B-Raf protein $[4,24]$. Furthermore, targeted deletion of PTEN in melanomas induced $\mathrm{BCl}_{2}$, which resulted in enhanced resistance to growth factor receptor inhibitors and chemotherapeutic agents $[8,9,20,21]$.

PTEN expression has been shown to inhibit melanoma cell proliferation and survival. Mechanistically, decreased PTEN activity alters cell cycle progression, migration, and adhesion of melanoma cells [14]. Recently, PTEN loss and ${ }^{\mathrm{V}}{ }^{000 \mathrm{E}} \mathrm{B}$-Raf have been shown to cooperate to promote metastatic melanoma development [24]. Furthermore, PTEN loss increased melanoma cell and nontransformed melanocytes invasion and migration by increasing Akt2 activity and by E-cadherin downregulation [25]. It is interesting that targeting PTEN differentially regulates Akt3mediated cell survival and Akt2-mediated metastasis in melanomas.

In addition to PI3K-Akt pathway regulation, PTEN also regulates the synthesis of proteins in melanoma cells. Mechanistically, PTEN controls phosphorylation of eukaryotic initiation factor- $2 \alpha$ (eIF $2 \alpha$ ), independent of its phosphatase activity, thereby inducing the antiproliferation and apoptotic signals [26]. Isogenic melanoma cells lacking PTEN had low phosphorylated eIF2 compared to cells expressing wildtype PTEN. Furthermore, reconstitution of wild-type or phosphatase-defective PTEN in PTEN-null human glioblastoma cells enhanced phosphorylation of eIF $2 \alpha$ via binding to PTEN's PDZ domain [26]. Phosphorylated eIF2 $\alpha$ inhibits eIF2B and blocks the initiation of translation and overall protein synthesis [26].

PTEN also regulates several key processes such as inhibition of cell proliferation by altering cell cycle progression through G1 to $S$ phase and control of apoptosis by modulating Akt activity [20, 27-29]. Furthermore, PTEN expression using a variety of vectors or from an introduced chromosome in melanoma cell lines lacking PTEN induced apoptosis and inhibited tumor development $[8,20,22]$. Cells containing functionally active PTEN protein exhibited elevated p27 expression, decreased cyclin-D1 and cyclin-D2 protein levels $[14,29,30]$.

1.2. Mechanisms Regulating the Expression and Activity of PTEN in Melanomas. PTEN expression and activity are regulated at transcriptional and posttranslational levels [15, $19,31]$ by positive regulators EGR-1 (early growth regulated transcription factor), PPAR $\gamma$ (peroxisome proliferatoractivated receptors), and p53 [19] as well as negative regulators MKK-4 (mitogen-activated protein kinase kinase 4), NF $\kappa \mathrm{B}$ (nuclear factor kappa-light-chain-enhancer of activated B cells), TGF- $\beta$ (transforming growth factor beta), and c-JUN $[14,19,32]$. At a posttranslational level, phosphorylation, oxidation, acetylation, and ubiquitination are key factors regulating PTEN activity [19, 33, 34]. For example, oxidation of cysteine residues $\mathrm{C} 71$ and $\mathrm{C} 124$ by reactive oxygen radicals inhibits PTEN phosphatase activity. Similarly, acetylation of PTEN catalytic domain lysine residues 125 and 128 by histone acetyltransferase PCAF (p300/CBPassociated factor) decreases affinity towards $\mathrm{PIP}_{3}$ 's thereby regulating melanoma development [35]. Other posttranslational modifications such as phosphorylation of the Cterminal tail serine and threonine residues (S362, T366, S370, S380, T382, T383, S385) by CK2 (casein kinase 2), LKB1, Src, GSK3 $\beta$ have been shown to play critical roles regulating PTEN activity by altering protein stability $[19,33]$. Phosphorylated PTEN is stable but less active compared to unphosphorylated PTEN $[19,36]$. For example, PTEN proteins either lacking the $\mathrm{C}$-tail or harboring mutations in C-tail are short lived [33, 36, 37]. However, it is not known whether such posttranslational modifications contribute to human melanoma development.

The subcellular localization of PTEN also plays a key role in melanoma development $[14,19]$ as PTEN has intrinsic membrane translocation signals in the phosphatase and C2 domains. Mutations in these regions and interactions with other proteins impair ability of PTEN to translocate to the plasma membrane. For example, ubiquitination of PTEN catalyzed by NEDD4-1 (neural precursor cell expressed, developmentally downregulated 4) influences 


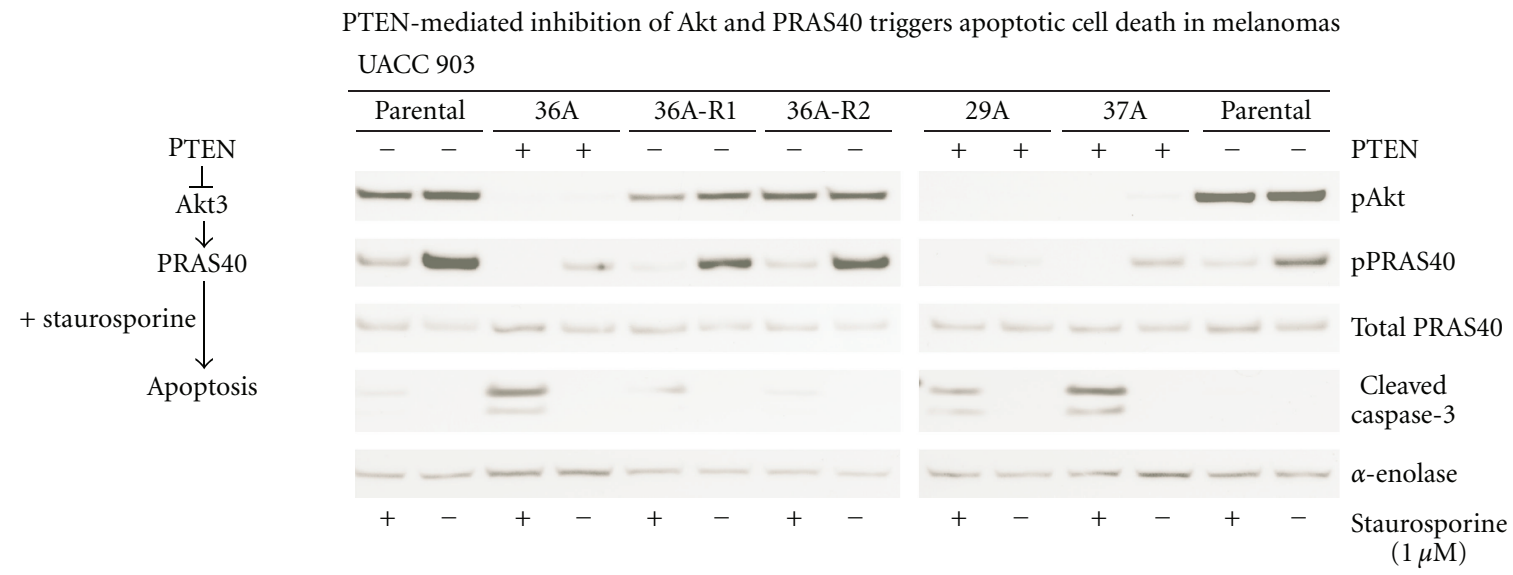

FIGURE 1: PTEN (EC number: 3.1.3.67) regulates Akt signaling in melanomas. Isogenic UACC 903 cell lines expressing (29A, 36A, 37A) or not expressing (parental UACC 903, revertant 36A-R1, 36A-R2) PTEN were treated with $1 \mu \mathrm{M}$ staurosporine for $4 \mathrm{~h}$ and cell lysates analyzed for the expression of pAkt, pPRAS40, and cleaved caspase-3. The data demonstrates that PTEN null cell lines express high pAkt, pPRAS40, and decreased cleaved caspase-3 fragments compared to cells harboring PTEN, indicating that PTEN sensitizes melanoma cells to chemotherapeutic agents [21].

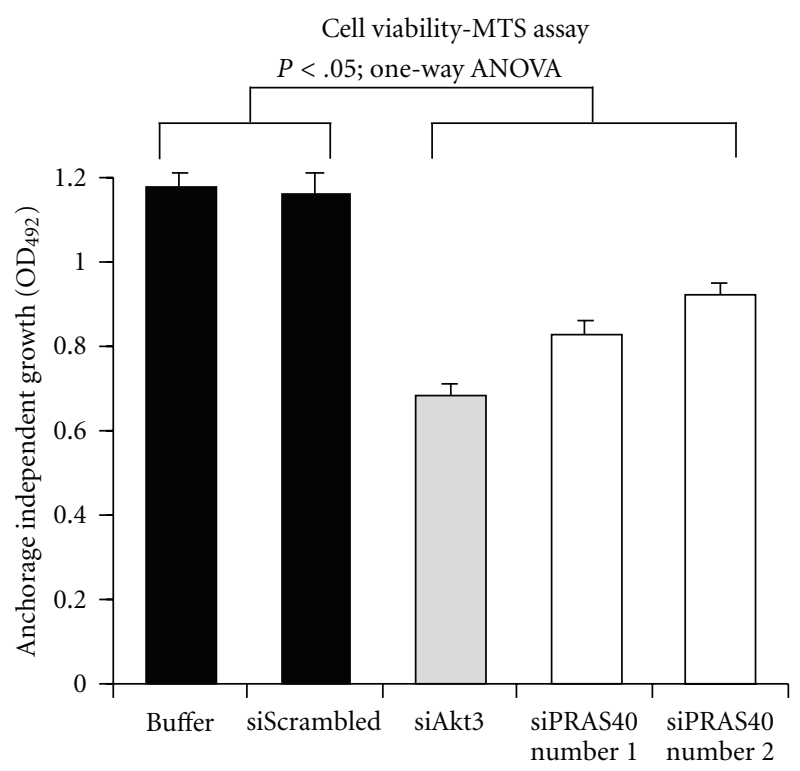

(a)

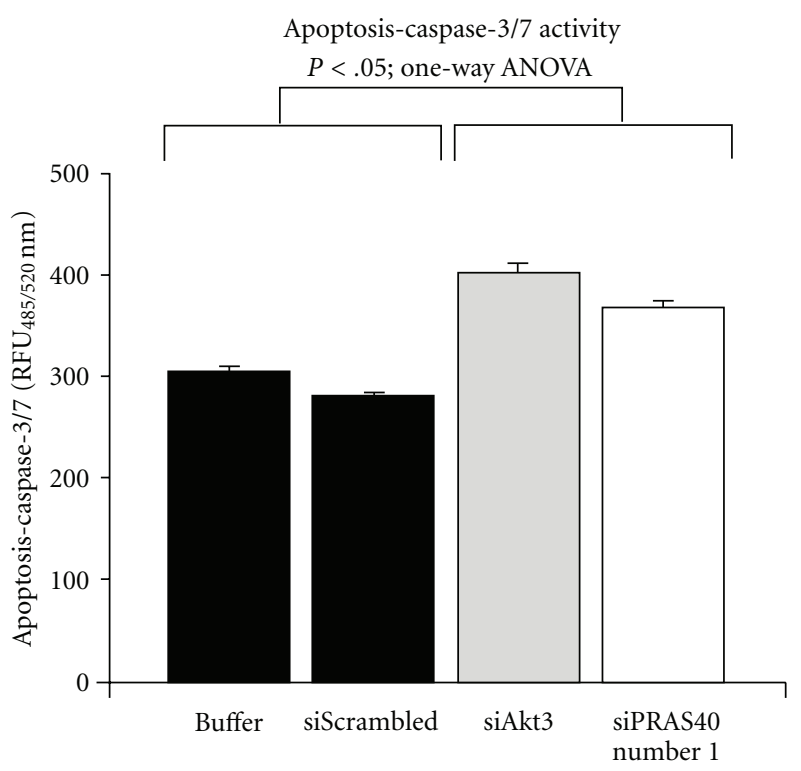

(b)

FIgure 2: Targeting Akt3 signaling inhibits melanoma cell survival. SiRNA-mediated targeting of Akt3 or downstream PRAS40 inhibited anchorage independent growth and induces caspase-3/7 activity in melanomas compared to control buffer or scrambled siRNA transfected cells [21].

its cellular localization, as monoubiquitination promotes nuclear localization while polyubiquitination causes PTEN protein to remain in the cytosol $[38,39]$. It would be interesting to determine whether similar ubiquitination patterns occur in melanomas.

Genetic and epigenetic mechanisms such as loss of a whole chromosome, mutations, and epigenetic miRNAs also modulate the expression as well as activity of PTEN $[18,19]$. For example, loss of chromosome 10 (the site of PTEN gene), occurs in $30 \%-60 \%$ of noninherited melanomas [8]. Similarly, screening of melanoma cell lines and paired uncultured metastatic melanoma to peripheral blood specimens for PTEN loss and/or alterations, found homozygous deletions in $\sim 20 \%$ melanoma cell lines, while $9 \%$ had nonsense, frame shift, or intronic mutations. However, only $\sim 12 \%$ of uncultured melanoma specimens contained nonsense mutations or homozygous deletions $[40,41]$. Intragenic polymorphisms in introns have also been reported to regulate PTEN expression in melanomas. Furthermore, $\sim 12 \%$ of melanomas have mutations in the PTEN gene $[40,41]$.

Early melanocytic lesions frequently have undergone loss of one allele of PTEN or haploinsufficiency occurring due to loss of the entire chromosome $10[14,42-45]$. Allelic 
loss or mutations of PTEN have been reported in 5\%-15\% of uncultured melanoma specimens and in 30\%-40\% of established melanoma cell lines $[40,41]$. Decreased PTEN levels due to haploinsufficiency plays an important role in early melanomas by specifically increasing Akt3 activity in these cells, thereby protecting these cells from apoptosis as well as releasing quiescent melanocytes from ${ }^{\mathrm{V} 600 \mathrm{E}} \mathrm{B}-\mathrm{Raf}$ induced cell senescence $[25,46-48]$. Loss or inactivation of PTEN also induces phosphorylation and monoubiquitination of DNA damage checkpoint kinase, Chk1, which then causes genomic instability, double-stranded DNA breaks, culminating in cancer development [41]. Amino acid altering mutations (P95S, F154L, L325F) induced by UV radiation have also been shown to impair PTEN function and thereby promote the development of early melanomas [49].

Epigenetic modifications such as methylation of $\mathrm{CpG}$ islands or microRNAs also regulate PTEN activity. For example, $\mathrm{CpG}$ islands methylation has been reported in melanomas [14, 50, 51]. Recently, PTEN promoter methylation leading to inactivation of transcription was found to occur in $\sim 62 \%$ of metastatic melanoma patients [52$60]$. However, contradictory to this observation, the most recent studies by Liu et al., 2008, and Bonazzi et al., in 2009, found no DNA methylation of the PTEN promoter $[61,62]$. Therefore, although regulation of PTEN expression by DNA methylation appears to be important, further studies are warranted to measure its contribution to melanoma development. If mutational and epigenetic silencing studies of PTEN are combined together, functional inactivation might occur in $\sim 77 \%$ of nonfamilial melanomas [54, 63-65].

1.3. PI3K Is a Key Regulator of Melanoma Development. Phosphatidyl inositol 3 kinases (PI3Ks) are a family of intracellular lipid kinases that phosphorylate the $3^{\prime}$ hydroxyl group of phosphatidylinositols (Pis) and phosphoinositides $[66,67]$. Activation of PI3K affects cell growth, proliferation and survival thereby influencing the tumorigenic potential of melanoma cells $[66,67]$. PI3Ks are classified based on substrate specificity and structure, into class-I, class-II, and class-III kinases [66, 68] (Figure 3). Whereas class-I PI3Ks convert PIP2 into PIP3, class-II, and class-III PI3Ks use PIs to generate PI-3-P. Class-I PI3Ks are further subdivided into class-Ia and class-Ib $[66,67]$. Activity of class-Ia PI3K is triggered by growth factor receptor tyrosine kinases, whereas class-Ib is activated by $\mathrm{G}$ protein-coupled receptors. Class-Ia $\mathrm{PI} 3 \mathrm{~K}$ is a heterodimer comprising of p 85 regulatory and p 110 catalytic subunits $[66,68]$. At the plasma membrane classIa PI3Ks phosphorylate PIP2 at the $3^{\prime}$ position and convert it into PIP3 upon growth factor stimulation. PIP3 binds to the $\mathrm{PH}$ domain containing PDK1 and Akt proteins leading to recruitment to the plasma membrane. In addition to lipid kinase activity, class-I PI3Ks also exhibit protein kinase activity. The physiological relevance of this activity differs between the members of class I PI3Ks. For example, classIa PI3K phosphorylates insulin receptor substrate-1 (IRS-1), whereas class-Ib PI3K activates the MAPK signaling cascade $[66,68]$.
PI3K-mediated activation of Akt occurs as a result of ligand-dependent activation of tyrosine kinase receptors, Gprotein-coupled receptors, or integrins [69]. Many of theses ligands are overexpressed in cancers, making this a route for Akt activation in melanomas [70, 71]. Receptor-independent activation of PI3K also occurs in 10\%-20\% melanomas expressing constitutively active Ras proteins [72-74]. Elevated PI3K activity itself can also cause Akt activation. Chromosome 3 q26 containing the p110 catalytic subunit of PI3K, which is frequently amplified in cancer of the ovary [75] and cervix [76], leads to increased PI3K catalytic activity. The importance of PI3K signaling in melanoma was demonstrated by overexpressing a deleted subunit of PI3K (Deltap85) to reduce PI3K signaling [77]. In this manner, Delta p85 functioned as a dominant-negative disrupting p85/p110 subunit interaction, consequently inducing apoptosis in the melanoma cell line G361.

$\mathrm{PI} 3 \mathrm{~K}$ is a critical regulator of melanoma progression. Targeting this kinase using siRNAs or pharmacological agents such as ZSTK474, which binds to ATP-binding pocket of PI3K, reduced melanoma tumor development $[66,68]$. In addition, preclinical studies have shown that therapeutic agents inhibiting PI3K activity synergizes with MAPK inhibitors. Although PI3K appears to be a critical regulator of melanoma development, to date, not many studies have shown its expression in patient tumor samples. Furthermore, results of publications are controversial, as some studies found no or low expression of PI3K in patient samples, while others have reported high level of expression $[66,68]$. Addressing this aspect a recent study quantitatively assessed the expression of PI3K in 523-melanoma and 540-nevi samples, and showed that p85 and p110 subunit expression is high in melanomas compared to nevi $[66,68]$. However, neither subunit served as prognostic marker in either primary or metastatic patients.

1.4. Akt3 Is Central to the Development of Melanomas. Akt, also known as protein kinase B, is a member of AGC family kinases and has three isoforms Akt1 $(\mathrm{PKB} \alpha)$, Akt2 $(\mathrm{PKB} \beta)$, and Akt3 $(\mathrm{PKB} \gamma)[71,78]$ (Figure 4). These three isoforms share $>80 \%$ homology and contain pleckstrin homology $(\mathrm{PH})$, catalytic and regulatory domains [70, 71, 78-84]. The N-terminal PH domain spans amino acids 1 to 107 , mediating protein-protein and protein-lipid interactions [85, 86], whereas the central catalytic domain (CD) contains a key phosphorylation residue $\mathrm{T}^{305}[87,88]$. The carboxy terminal regulatory domain (RD), also referred as hydrophobic motif (HM), contains a second phosphorylation site serine $\left(\mathrm{S}^{472}\right)$, whose phosphorylation is required for complete activation of this kinase. Other possible phosphorylation sites may also be important, and research in this area continues [89]. In one study it has been shown that the E40K mutation enhances the enzymatic activity of Akt3 in melanomas [21, 46]. Splice variants of Akt3 lacking serine 472 have been identified but the significance of this form of the protein remains unknown $[90,91]$.

Akt is a positive regulator of cell proliferation and survival, which are controlled by various growth factors and 


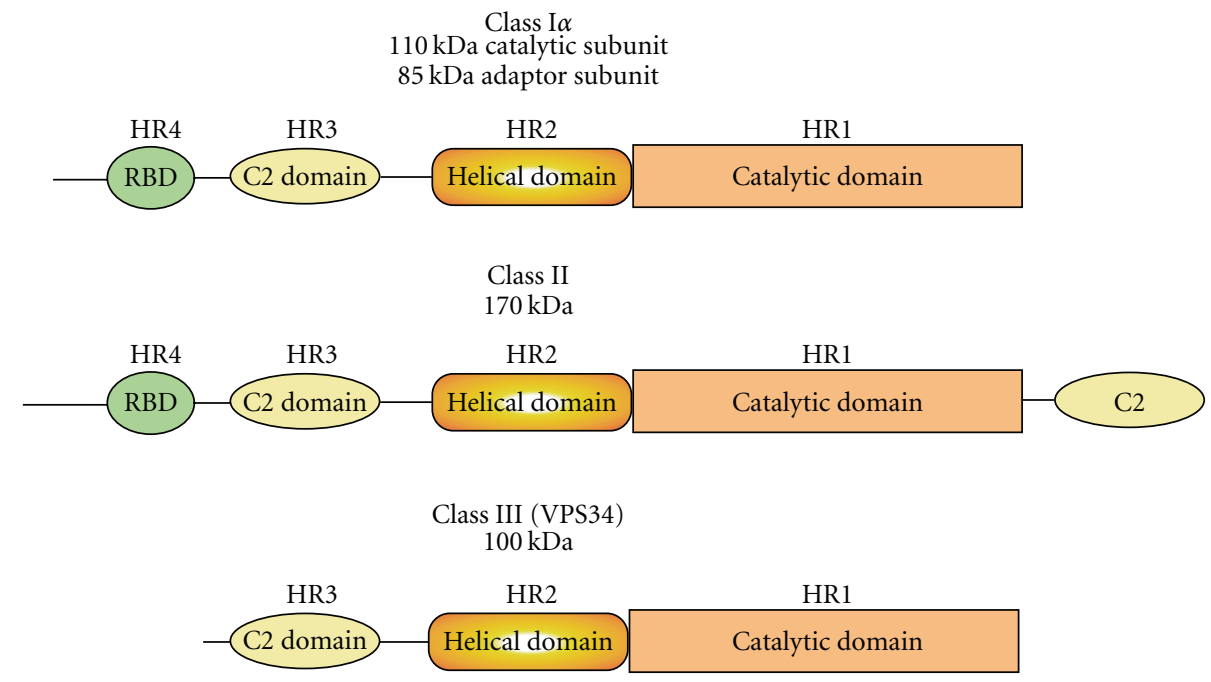

FIgURE 3: Schematic representation of PI3 kinase enzymes. PI3 kinases are a group of enzymes involved in regulating cell growth, proliferation, differentiation, motility, and survival. Based on structure and substrate specificity PI3 kinases have been divided into Class I (EC number: 2.7.1.153), Class II (EC number: 2.7.1.154), and Class III (2.7.1.137) enzymes. Class I and II PI3Ks are composed of regulatory and catalytic subunits, whereas Class III contains only catalytic subunit. Depending on the type of subunits, heteromeric Class I PI3Ks are further subdivided into Class IA and Class IB. Whereas Class IA PI3K consists of p85 regulatory subunit and p110 catalytic subunit, the Class IB PI3K is made up of p101 regulatory subunit and p110 $\gamma$ catalytic subunit. Class IA PI3K is the most common PI3Ks implicated in the development of cancers.

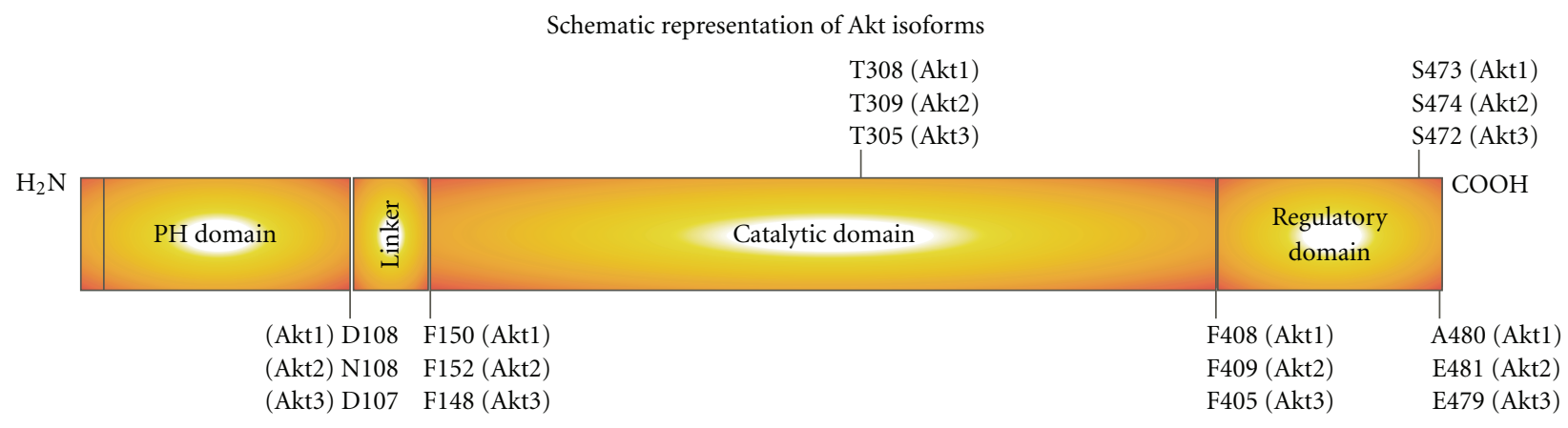

FIGURE 4: Schematic representation of Akt kinases (EC number: 2.7.11.1). Akt, also known as protein kinase B, is a serine, threonine protein kinase implicated in the development and chemotherapeutic resistance of cancers. Although the three isoforms, Akt1, Akt2, and Akt3, share high degree of structural homology in terms or domain ( $\mathrm{PH}$, catalytic, and regulatory) architecture, they exhibit variations in some of the key amino acid residues and cellular functions. Domain organization and key phosphorylation site are represented.

extracellular stimuli (Figure 5) [10]. Despite sharing high degree of homology and some cellular activities, Akt1, Akt2, and Akt3 also exhibit isoform-specific functions [92, 93]. Studies using isoform-specific knockout mice have demonstrated that Akt1 has a key role in maintaining cell survival [93]. Akt1 knockout mice are smaller compared to wild-type mice, and cells lacking Akt1 undergo apoptotic cell death [93, 94]. Likewise, Akt2 knockout mice developed type2 diabetes, whereas mice lacking Akt3 displayed impaired brain growth $[95,96]$. However, not much is known about how these isoform-specific functions are regulated. Some of the key factors regulating isoform-specific functions of Akt include (a) differential tissue distribution [93], (b) differences in the Akt responses to extracellular stimuli [97, 98], (c) structural variations in the key domains regulating translocation, substrate binding, and catalytic activity [10, 99], and finally (d) intracellular compartmentalization [93, 97].

Aberrant activation of Akt kinases has been reported in several malignancies including melanoma. Mechanisms leading to Akt activation can involve (a) mutations in the upstream regulators PI3K and PTEN; (b) overexpression of the gene due to increased copy number or activating point mutations in Akt itself, (c) deletion of negative regulators such as PTEN; (d) altered expression of interacting proteins such as TCL1, HSP90, APPL1, and RasGAP $[5,6,8,67]$. Akt activity is also regulated by posttranslational modifications such as phosphorylation, ubiquitination and also by physical interactions with effector proteins such as Hsp90 and Pin1 $[92,100,101]$. Although physiological functions of Akt 

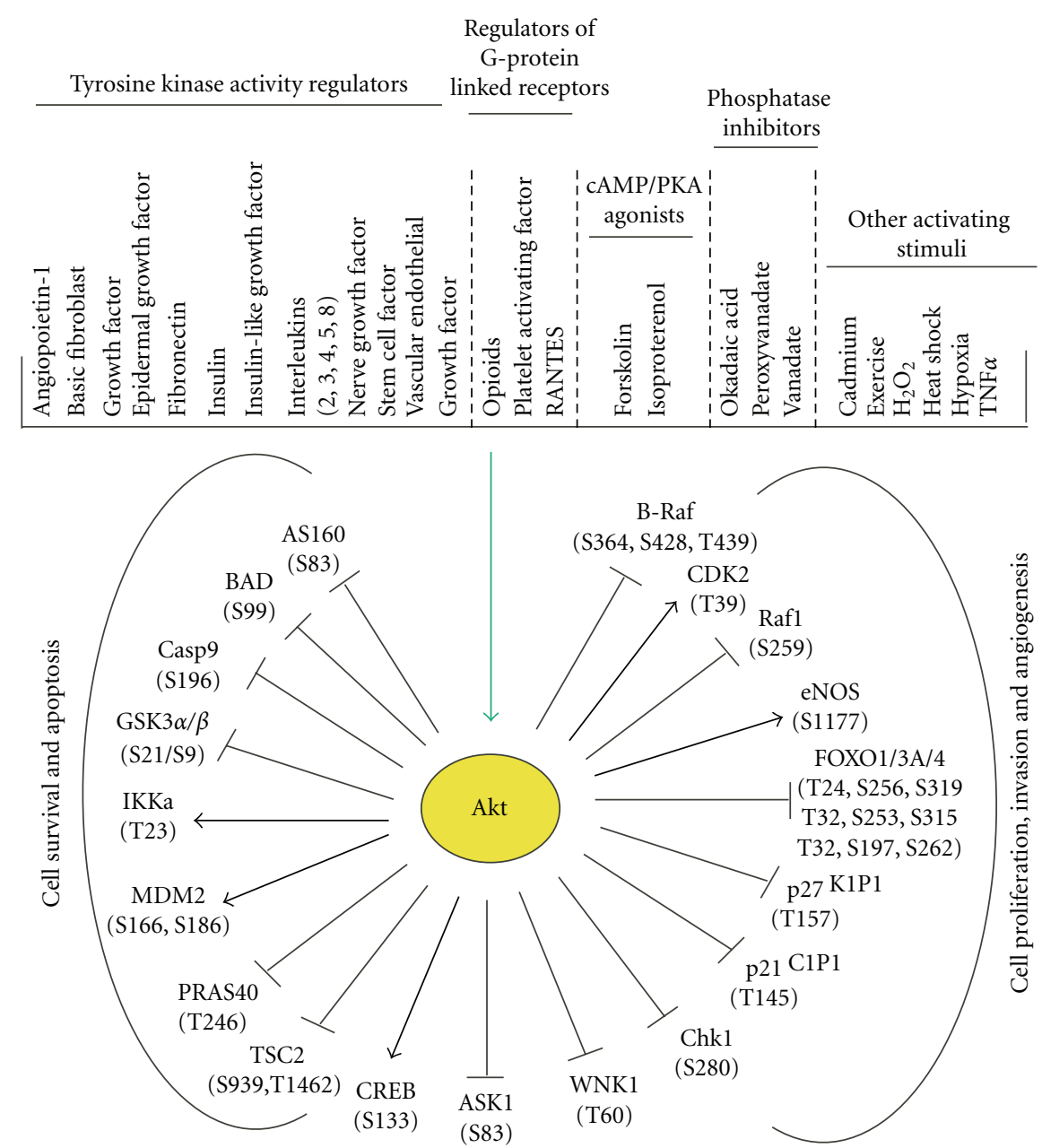

FIGURE 5: Akt is the key regulator of cell survival and proliferation. Growth factors and hormones trigger the Akt pathway by a series of phosphorylation and dephosphorylation events. Shown are some of the substrates of Akt implicated in cell survival, proliferation, and migration.

isoforms are regulated through similar mechanisms, the activity of a particular isoform is cell type dependent [70, 71, 78-84].

Translocation to the cell membrane followed by phosphorylation of key amino acid residues activates Akt signaling. In normal cells, Akt is cytoplasmic and inactive. Upon growth factors binding to a cell surface receptor or through G-protein-coupled receptors, PI3K gets activated, which, then phosphorylates phosphatidylinositol-4,5-bisphosphate $\left(\mathrm{PIP}_{2}\right)$ on the $3-\mathrm{OH}$ group, generating second messenger phosphatidylinositol-3,4,5-trisphosphate $\left(\mathrm{PIP}_{3}\right)$ [102]. $\mathrm{PIP}_{3}$ binds to the $\mathrm{PH}$ domain of Akt thereby facilitating translocation to the plasma membrane. Akt activation is initiated when the translocated Akt is phosphorylated on T308 residue by membrane-localized phosphoinositidedependent kinase-1 (PDK-1). However, complete activation is achieved only when a PDK2 phosphorylates the second phosphorylation site S473. Recent studies have shown that serine 473 phosphorylation is mediated by rapamycininsensitive mTORC2 $[103,104]$. PDK2 activity of the mTOR complex has been recently established but in melanomas its role in maintaining Akt3 phosphorylation has not been studied $[103,104]$. Akt autophosphorylation might also play a role in the activation process [70, 71, 78-84]. Furthermore, it has been shown that prior phosphorylation of tyrosine 315 (Y315) and 326 (Y326) residues is a prerequisite for the activation of Akt kinases (Figure 4).

Preferential activation of a specific Akt isoform has been reported in cancers of breast, ovarian, pancreas, and skin [93]. For example, Akt2 gene amplification has been observed in ovarian and pancreatic cancers. Similarly, Akt3 found to be selectively activated in melanomas $[5,6,9]$. Therefore, selective activation of a speficic Akt isoform appears to regulate the development of a particular cancer. But, to date, the mechanistic basis for this isoform-specific regulation is not known and slowly starting to emerge [93].

Akt activity is also regulated by dephosphorylation of phosphorylated Thr308 and Ser473. Phosphatases are the key enzymes controlling phosphorylation status of Akt. Whereas PTEN dephosphorylates secondary messenger PIP3 into PIP2, the protein phosphatase 2A (PP2A) and $\mathrm{PH}$ domain leucine-rich repeat protein phosphatase (PHLPP) 
remove phosphate groups from T308 and S473, respectively, to deactivate Akt kinases [92, 105, 106]. Okadaic acid, a strong inhibitor of PP2A, promotes phosphorylation of Akt, whereas ceramide, an activator of PP2A, reduces Akt activity $[92,107,108]$. Although extensive studies have been reported on the critical role of PTEN phosphatase, not much is known about the status of PP2A and PHLPP in melanomas.

Another posttranslational modification that has been shown to regulate Akt activity is ubiquitination. Ubiquitination-dependent upregulation of Akt activity has been reported in various cancers $[92,100]$. Studies have demonstrated that TRAF6 E3 ligase is required for Akt ubiquitination [109]. Cells overexpressing TRAF6 exhibit high Akt kinase activity, whereas TRAF6 null cells had negligible phosphorylated active Akt [109]. Experiments measuring the effect of TRAF6 expression on Akt activity before and after translocation revealed that TRAF6 is essential for membrane translocation of Akt, but once the Akt is bound to cell membranes, TRAF6 has no effect on regulating Akt activity $[100,109]$.

Primary structure of Akt also influences its activity. Since the constituent amino acid sequences, especially ubiquitination sites, are involved in regulating protein stability, mutations in these key sites might influence the protein stability thereby enzyme activity. For example, site-directed mutagenesis analysis showed that ubiquitination of Akt occurs at $\mathrm{K} 8$ and $\mathrm{K} 14$ residues located in the $\mathrm{PH}$ domain [100]. Growth-promoting somatic mutations in the PH domain of Akt have been reported in several cancers [92, $100,110]$. For example, E17K mutation in Akt is found in cancers of breast $(8 \%)$, colon $(6 \%)$, skin $(1.5 \%)$, and ovaries (2\%) $[92,99,100,110,111]$. Similarly, E49K mutation is identified in a subset of bladder cancer patients [112]. However, the abundance of E17K mutation is either too low, or, in some instances, no such mutations were found making it difficult to consider this as a biomarker of tumor progression. For example, in nonsmall cell lung cancers and acute myelogenous leukaemias no such mutations in Akt1 were identified [113, 114]. Moreover, no differences in the ability to translocate to the plasma membrane were observed in experiments where the PH domain of Akt1 was switched with Akt2 $\mathrm{PH}$ domain indicating that it is not just the $\mathrm{PH}$ domain mediating translocation of the protein but other factors such as posttranslational modification, which might also play a role [93]. Thus, basal Akt activity in a cell primarily depends upon several factors regulating subcellular localization, specifically a balance between positive and negative regulators controlling Akt phosphorylation status and proteins that interact with the kinase itself.

\section{Functional Characterization of Akt3 Signaling in Human Melanomas}

2.1. Akt3 Is a Key Protein Kinase Regulating Melanoma Development and Chemotherapeutic Resistance. Increased Akt3 expression/activity occur in $60 \%-70 \%$ of sporadic melanomas demonstrating a key role in melanoma development $[23,115]$. Activated Akt3 phosphorylates several substrate proteins containing Arg-X-Arg-X-X-[Ser/Thr]-Hyd (where $\mathrm{X}$ is any amino acid and Hyd is a bulky hydrophobic amino acid) consensus sequences thereby regulating cellular survival and chemotherapeutic resistance (Figure 5). For example, phosphorylation of (a) GSK3 $\beta$ inhibits its activity thereby promoting cell cycle progression through increased cyclin D levels [116, 117]; (b) PRAS40 at threonine $246\left(\mathrm{~T}^{246}\right)$ inhibits the interactions with mTORC1 thereby increasing the nutrient status of the cells $[21,118,119]$; (c) ${ }^{\mathrm{V} 600 \mathrm{E}} \mathrm{B}-$ Raf decreases its activity to levels that promote rather than inhibit cell proliferation [46, 120]; (d) osteopontin, a glycophosphoprotein, promotes melanoma progression levels to a highly metastatic state [121]. Furthermore, Akt3 inhibits cellular apoptosis by decreasing caspase-3/7 activity and increasing the expression of cleaved caspase- 3 and cleaved PARP levels $[9,122]$. Decreased apoptosis makes melanoma cells less sensitive to chemotherapeutic agents functioning through this mechanism.

Increased Akt3 activity also plays a significant role in progression to more advanced aggressive tumors $[6,21$, 23]. For example, expression of Akt3 has been elevated in cell lines derived from primary melanoma tumors at the radial and vertical stages of cell growth compared to normal human melanocytes (Figure 6). No significant changes were observed in the levels of Akt1 and Akt2 in the same lysates, indicating that Akt3 activation performs critical functions in melanoma development $[6,23]$. Consistent with this observation, a recent report also showed elevated Akt3 expression in melanoma cell lines having high pAkt [123]. Analysis of a panel of 58 melanoma cell lines and 96 melanoma metastases showed elevated pAkt in cells harboring a mutant ${ }^{\mathrm{V} 600 \mathrm{E}} \mathrm{B}$-Raf compared to cells containing $\mathrm{N}$-Ras [123]. However, it is unknown why Akt3 and not the other isoforms is activated in melanomas. Various explanations with experimental evidence have provided some clues by demonstrating (a) increased copy numbers of the Akt3 gene compared to other isoforms in melanomas, which might contribute to some extent for the preferential Akt3 activation [14, 23] and (b) selective activation of Akt3 by preferentially interacting with $\mathrm{PIP}_{3}$ and/or accessory proteins that bind to $\mathrm{PH}$ domain of Akt3 but not to Akt2 or Akt1. Structurally Akt3 has different phosphorylation sites within the $\mathrm{PH}$ domain compared to other Akt isoforms [70, 71, 7884]. For example, TCL1 selectively binds to the Akt3 PH domain, thereby promoting hetero-oligomerization of Akt1 with Akt3, causing transphosphorylation of Akt in leukemias [124-126]. Thus, factors interacting preferentially with Akt3 may lead to selective activation in melanomas.

Recent studies have identified another mechanism for isoform-specific regulation of Akt signaling. These studies have shown that the phosphatidylinositol 3-phosphate binding FYVE domain-containing protein WDFY2, localizes to a distinct subset of early endosomes that are close to the plasma membrane thereby serves as a molecular scaffold to regulate the phosphorylation of Akt kinases in an isoformspecific manner [127]. For example, WDFY2-depleted cells expressed very low levels of Akt2 and pAkt compared to 


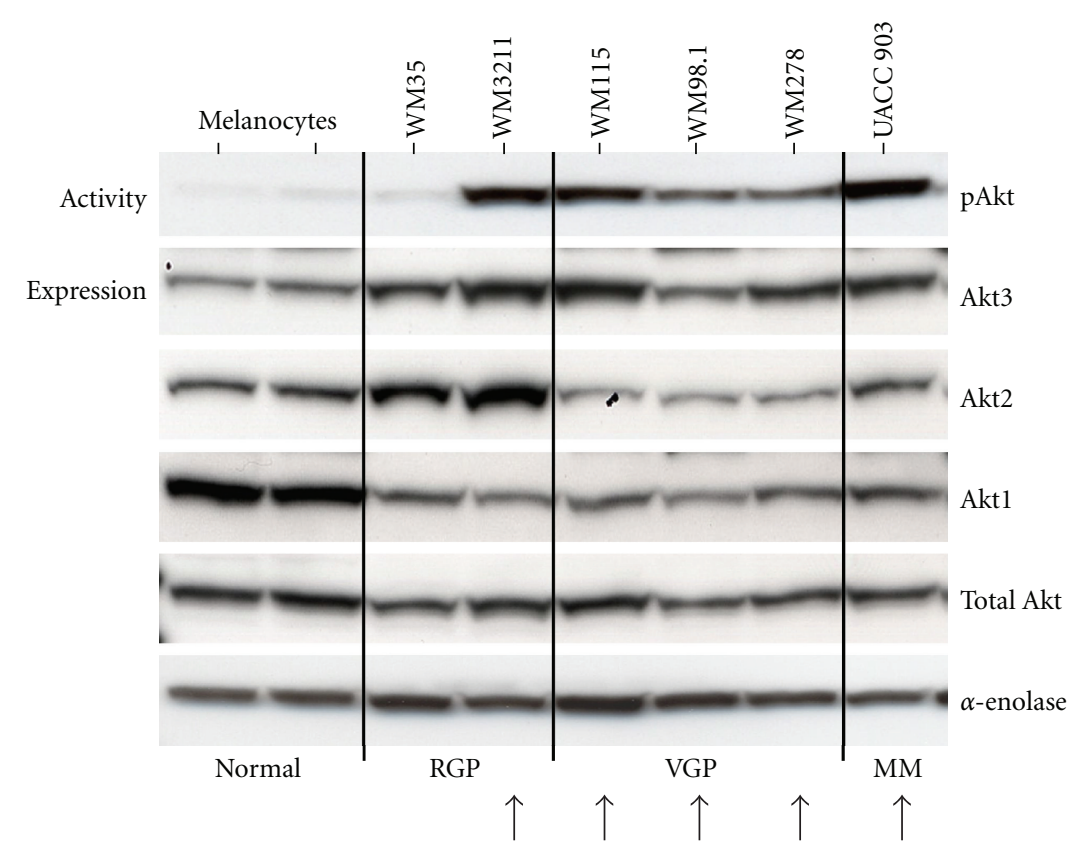

FIGURE 6: Akt3 but not Akt2 or Akt1 is upregulated in the majority of melanoma cells. Protein lysates were harvested from melanocytes and melanoma cell lines representing radial (WM35, WM3211), vertical (WM115, WM98.1, and WM278), and metastatic (UACC 903) stages and analyzed by western blotting. Arrows indicate the cell lines expressing high Akt3 and pAkt. Note. Expression of Akt1 and Akt2 is not changed in majority of advanced melanomas, indicating that Akt3 is the key regulator of cell survival in melanomas [9].

control cells containing WDFY2. Similarly another study also demonstrated the endosome mediated, isoform-specific regulation of Akt activity and substrate selectivity [127]. Rab5 effector endosomal protein Appl1 interacts with transmembrane receptors and Akt thereby influencing Akt activity and substrate selectivity [128]. Human adaptor protein containing PH domain, PTB domain, and leucine zipper (Appl1) is an Akt-interacting protein involved in the regulation of cell survival and proliferation [128]. Targeted depletion of Appl1 decreased phosphorylation of GSK3 but not TSC2 indicating the substrate selectivity induced by this endosomal protein [128]. However, it is not known whether similar regulatory mechanisms also occur in melanoma. We now know that GSK3 regulates cell survival and proliferation rates of melanoma cells but whether Appl1 regulates GSK3 activity in melanoma is not known. Addressing this might open up new avenues for understanding the mechanistic basis of Akt-mediated cell survival regulation and help designing potent therapeutic agents to inhibit this signaling cascade in melanomas.

A central role of the Akt3 isoform in melanoma development is well established; however, a recent report using human melanoma biopsy samples found Akt2 as a predominantly activated isoform in melanomas [129]. In addition, a different study demonstrated that loss of PTEN promoted melanoma cell metastasis via activating Akt2 but not Akt1 or Akt3 [25]. Interestingly, this study also demonstrated that expression of myrAkt 3 inhibited invasion of melanoma cells without influencing the expression levels of pFAK and pSTAT3 [25]. Mechanistically, Akt2 induces the expression of miR-200 microRNAs thereby decreasing the expression of E-Cadherin [25], which in turn increases cell invasion. Therefore, it might be interesting to study whether different isoforms of Akt have different functions in regulating melanoma tumor development and metastasis, and if so, how this preferential regulation is occurring. These studies will help addressing some of the key aspects of Akt signaling in melanomas and provide new insights for understanding the mechanistic basis of melanoma tumor development.

2.2. Mechanism Promoting Akt3 Deregulation in Melanomas. A key mechanism for increased Akt activity in cancer cells involves gene copy number increases or mutations leading to constitutive activation. Recently a low-frequency activating mutation $(\mathrm{E} 17 \mathrm{~K})$ in the $\mathrm{PH}$ domain of Akt3 has been identified in melanoma cell lines and $\sim 4 \%$ of patient tumors [111]. This mutation enables Akt3 to get recruited to cell membranes independent of PI3K, which leads to cellular transformation. Genetic amplifications increasing Akt1 or Akt2 expression occur in carcinomas of the stomach, ovary, pancreas, and breast [130-137]. Specifically, Akt2 amplification occurs as part of the 19q13.1q13.2 amplicon in high-grade aggressive ovarian tumors [138]. Even though no amplifications of Akt genes have been reported in melanomas $[139,140]$, Akt3 protein is frequently overexpressed [23], as a result of copy number increases of the long arm of chromosome 1 containing the gene [4345]. No increases in the long arms of chromosome 14 or 19 containing the Akt1 and Akt2 genes, respectively, have been reported [43-45]. Thus, increase in Akt3 copy number is one mechanism contributing to increased expression and 


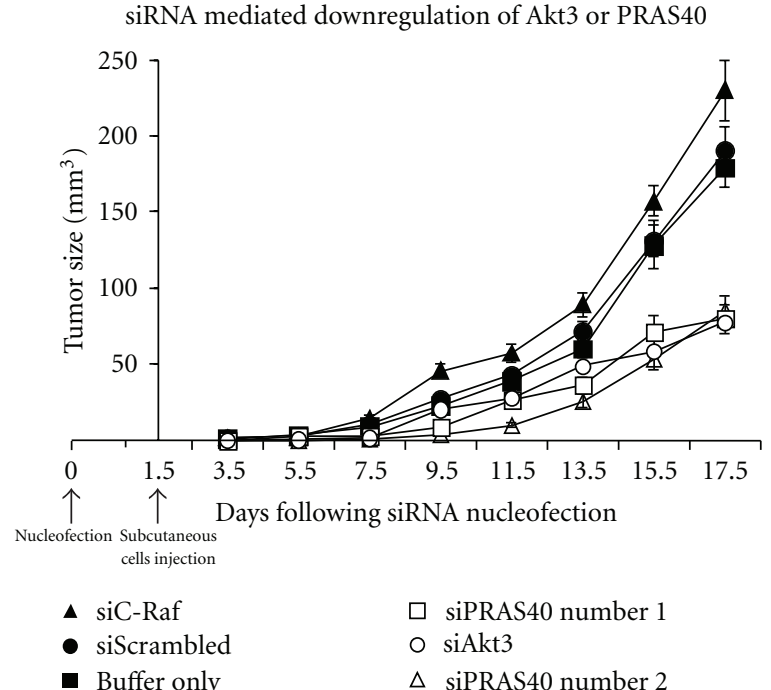

(a)

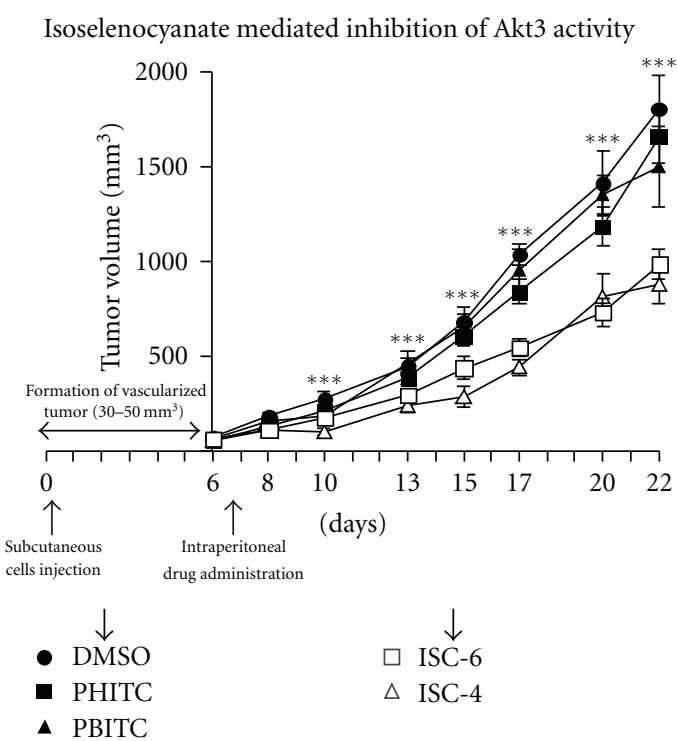

(b)

FIGURE 7: Targeting Akt3 inhibits melanoma tumor development. SiRNA targeting Akt3 and downstream PRAS40 is introduced into UACC 903 melanoma cells by Amaxa transfection and effect on xenografted subcutaneous tumors measured. The data shows 50\%-60\% decreased tumor volume when the expression of Akt3 and PRAS40 is inhibited compared to control cells transfected with a scrambled siRNA, siRNA to C-Raf, or buffer [21]. Inhibiting Akt activity using pharmacological agent ISC-4 that contains selenium also reduced melanoma tumor growth as effectively as siRNA mediated downregulation of Akt3 expression, indicating the potential utility of developing pharmacological agents targeting this key protein in melanomas [122].

activity in melanoma. Since expression of Akt3 protein might not represent the activation status of the protein, it is thought that other processes must also contribute, leading to preferential activation of Akt3 versus the other isoforms in melanomas.

Phosphatases that directly dephosphorylate Akt may also play a role in the preferential activation of Akt3 in melanomas. While the identity of these phosphatases remains uncertain, $\mathrm{PP} 2 \mathrm{~A}$ phosphatase may be involved in this process [141]. Proteins binding to Akt also have the potential to modulate cellular activity as is observed with the protooncogene TCL1, which enhances oligomerization of Akt1 with Akt3, thereby facilitating activation of Akt3 in leukemia [124-126]. Another example is the heat-shockprotein 90 (Hsp90) that can complex with Akt. Inhibition of Akt-Hsp90 complex formation can inactivate Akt by PP2Amediated dephosphorylation [142, 143].

Deregulated Akt3 expression and activity could also be controlled by noncoding microRNAs. For example, miR-149 has been shown to inhibit Akt1 activity thereby inducing apoptosis in neuroblastoma and cervival cancers [144]. Ectopic expression of miR-149 induced apoptosis by inhibiting Akt1 expression and activity [144]. However, miRNAs specifically regulating Akt3 expression have not been identified. Only recently, miRNAs $15 \mathrm{a}$ and 16 have been shown to inhibit the expression of Akt3 in multiple myelomas [145]. However, these miRNAs also inhibited ribosomal protein-S6, MAP-kinases, and NF- $\kappa$ B activator MAP3KIP3 [145]. Discovering miRNAs specifically regulating Akt3 is important to assess the clinical progression of the disease and for developing novel tools for preventing or treating melanomas.

\section{Cellular Processes Regulated by Akt3 Signaling in Melanomas}

3.1. Akt3 Signaling Regulates Cell Survival, Migration, Metastasis, and Chemoresistance. Akt3 has been shown to be a prosurvival kinase in melanomas [23]. SiRNA or pharmacological agents targeting Akt3 protein levels or expression of PTEN selectively lowers Akt3 activity, thereby reducing the tumorigenic potential of melanoma cells by altering apoptotic sensitivity of the cells (Figure 7) [21, 23]. Furthermore, increased activity correlates with tumor progression, providing cells with a selective advantage in the tumor environment $[21,23]$. Inhibiting Akt signaling in tumor cells by adenoviral transfer of an Akt kinase-dead mutant, in which the two regulatory phosphorylation sites have been mutated to alanines thereby converting it to a dominant negative, led to selective induction of apoptosis in tumor cells expressing activated Akt [146]. In contrast, a minimal effect was observed in normal or tumor cells expressing low levels of active Akt [146]. In addition, a recent study showed that Akt could act as a molecular switch by increasing angiogenesis and producing superoxides [147]. Experimentally, overexpression of Akt in radial growth phase WM35 cells transformed them into malignant phenotypes by stabilizing 
cells with extensive mitochondrial DNA mutations, which can generate ROS, and by inducing expression of NOX4, a ROS generating enzyme [147].

The vital role of Akt in melanoma tumor progression and development is further confirmed by showing that hyperactivated Akt signaling upregulated Notch1 via NF $\kappa$ B activity thereby inducing the transformation of melanocytes under prevailing hypoxic conditions in tumors [148]. Upregulated Akt activity in melanoma tumors appears to protect cells from low oxygen pressures and apoptotic cell death induced by various chemotherapeutic agents [48]. For example, a recent study demonstrated that Akt3 mediates the resistance to apoptosis in B-Raf-targeted melanomas [48]. Targeting ${ }^{V 600 E}$ B-Raf using PLX-4072 rendered invasive melanoma cells susceptible to anoikis, a form of apoptosis generally induced by loss of adhesion and is mediated by BH3-only proteins, Bim-EL and Bcl2-modifying factor (Bmf) $[48,149]$. However when expression of Akt3 is induced by adhesion to fibronectin in these cells, the cells exhibited resistance to apoptosis caused by B-Raf inhibition [48]. Therefore, Akt3 is a key regulator of melanoma cell survival and helps protect cells from apoptosis induced by chemotherapeutic agents [48]. Another recent study also demonstrated the induction of chemotherapeutic resistance by Akt activation. Human melanoma cells under endoplasmic reticulum stress showed more resistance to apoptosis induced by microtubuletargeting chemotherapeutic agents such as docetaxel and vincristine, which is mediated by Akt activation [150].

Processes such as metastasis, cell-cell adhesion, cell migration, and development of chemoresistant tumors under hypoxic conditions are also regulated by PI3 kinase and Akt signaling pathways $[6,147,152]$. Activated Akt in metastatic melanoma cells have been shown to regulate Notch1 expression via $\mathrm{NF} \kappa \mathrm{B}$ thereby promoting tumor development under hypoxic tumor conditions [148]. A different study has shown that Akt inhibits RhoB, a GTPase, in melanomas and thereby induces tumor cell survival, transformation, invasion, and metastasis [153].

\subsection{Substrates of Akt3 Kinase Involved in Melanoma Develop-} ment. Akt substrates can be cytoplasmic or nuclear proteins, and numbers of proteins regulated by Akt continue to increase as studies such as those using the minimal consensus peptide sequence Arg-X-Arg-X-X-[Ser/Thr]-Hyd (where X is any amino acid and Hyd is a bulky hydrophobic amino acid) search for putative substrates $[154,155]$. The functions of many of these substrates in cellular processes have been identified, demonstrating that Akt regulates multiple processes in cells including apoptosis and proliferation (Figure 5).

Substrates for Akt3 do not appear to be specific but rather seem to be identical to those acted on by all three Akt isoforms. Substrates of Akt3 involved in melanoma development include (a) Bad-whose inactivation promotes cell survival [156]; (b) NFאB-inhibition of Akt activity led to increased apoptosis and decreased $\mathrm{NF} \kappa \mathrm{B}$ promoter activity in melanoma cells [115]; (c) hTERT-inhibition of Akt reduced hTERT peptide phosphorylation and telomerase activity
[157]; and (d) Rac1-targeting Akt decreased phosphorylated serine 71 of Racl thereby modulating the Racl signal transduction pathway in SK-MEL-28 melanoma cells [158] (Figure 5).

Recently, Akt3 has been reported to phosphorylate ${ }^{\mathrm{V} 600 \mathrm{E}} \mathrm{B}$-Raf on S364 and/or S428 to reduce its activity to levels that promote rather than inhibit melanoma development from melanocytes [46]. Ectopic expression of ${ }^{\mathrm{V} 600 \mathrm{E}} \mathrm{B}-\mathrm{Raf}$ in primary cell lines such as melanocytes has been shown to induce cellular senescence not only by elevating the levels of MAPK activity for unusually longer periods but also by upregulating the expression of cyclin-dependent kinase (cdk) inhibitors $[159,160]$. Therefore, genetic changes such as loss of tumor suppressor genes (PTEN, p53 or p16INK4A) or upregulation of cooperating oncogenes is necessary to progress into advanced metastatic stages [161]. For example, activation of Akt3 has been demonstrated to facilitate the progression of quiescent melanocytic nevi into aggressive vertical and metastatic stages by inhibiting ${ }^{\mathrm{V} 600 \mathrm{E}} \mathrm{B}$-Raf activity thereby releasing cells from a senescence block [46, 162]. This demonstrates that in melanomas, Akt3 kinase not only increases cell survival but also aids early melanoma development [46]. Likewise, a recent study demonstrated the induction of melanomas only when PTEN is silenced [47]. Using a conditional mouse model it has been demonstrated that ${ }^{\mathrm{V}}{ }^{60} \mathrm{E} \mathrm{B}-\mathrm{Raf}$ induction resulted in the development of melanocytic hyperplasias, which failed to progress into melanomas [47]. However, when the PTEN gene was silenced while maintaining the expression of ${ }^{\mathrm{V} 600 \mathrm{E}} \mathrm{B}-$ Raf, melanocytic hyperplasias progressed into melanomas with $100 \%$ penetrance, short latency, and metastatic ability [47].

PRAS40 is another substrate regulated by Akt3. PRAS40 is a cytosolic protein found ubiquitously in all eukaryotes [118] and is phosphorylated by Akt at T246 [118]. Phosphorylated PRAS40 ${ }^{\mathrm{T} 246}$ protects neuronal cells from ischemic injury by inhibiting caspase-3-mediated apoptotic cell death [163]. Expression of pPRAS40 levels are also associated with tumor malignancy [164]. Compared to paired control normal cells, cancer cell lines (MCF10A/MCF7, BEAS/H1170) exhibited high pPRAS40 expression [164]. However, the detailed functional characterization, in vitro and in vivo, was not reported. Compared to normal melanocyte controls, 43 to $60 \%$ of flash frozen tumors collected from melanoma patients express high pPRAS40 and pAkt [21]. Furthermore, targeted inhibition of PRAS40 using siRNA reduced melanoma tumor growth in xenografted melanoma studies (Figure 8) [21]. Mechanistically, PRAS40 inhibition induced caspase-3/7-mediated apoptosis in melanoma cells and increased sensitivity to apoptosis inducers such as staurosporine [21]. However, the molecular basis for caspase3/7 activity inhibition by pPRAS40 in melanomas remains unknown.

Recent reports have demonstrated that PRAS40 is a physiological target of mTORC1 kinase and regulates its activity by functioning as a direct inhibitor of substrate binding [119, $165,166]$. PRAS40 has two additional phosphorylation sites S183 and S221 other than the one phosphorylated by Akt [167]. A recent study demonstrated that phosphorylation 


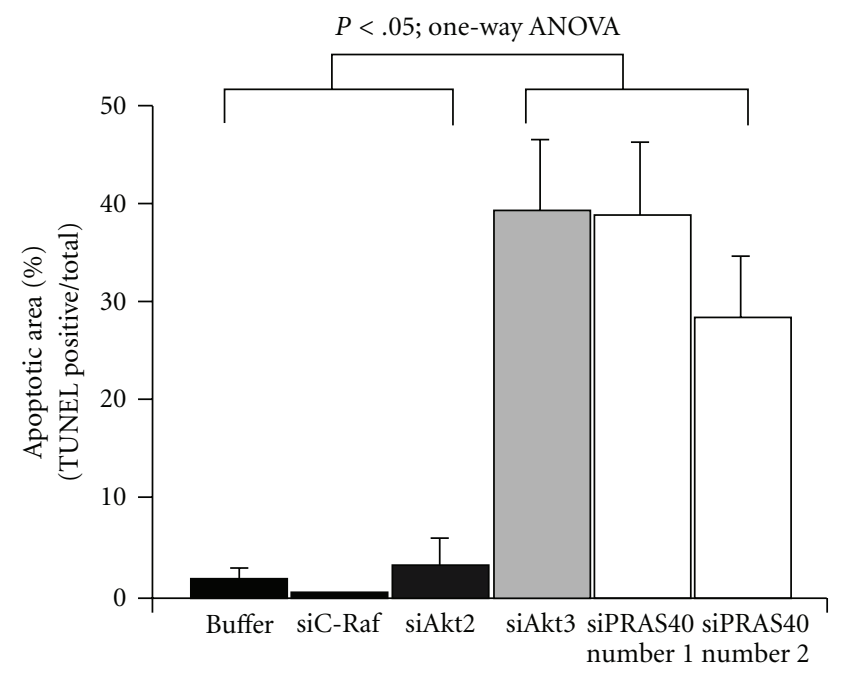

(a)
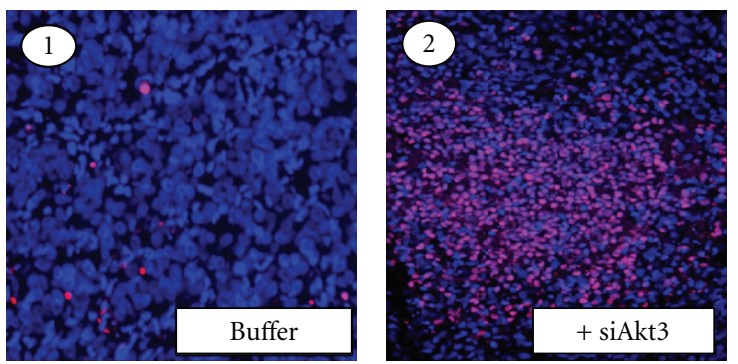

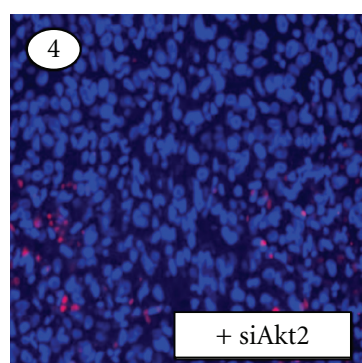

(b)

FIGURE 8: Akt3 and downstream PRAS40 are the key regulators of melanoma cell survival. SiRNA-mediated downregulation of Akt3 and PRAS40 induced apoptosis in subcutaneous melanoma tumors. Shown are the representative pictures of TUNEL assay performed on sizeand time-matched tumors. The bar graph shows the percentage TUNEL positive cells in the tumors [21].

of T246 by Akt facilitates the phosphorylation of S183 and S221 by mTORC1 [167]. 14-3-3 proteins via physical interactions sequester phosphorylated PRAS40 thereby release mTOR. Therefore, increased pPRAS40 ${ }^{\mathrm{T} 246}$ may releasing its inhibitory effects on mTORC1 kinase and downregulate caspase-3/7 activity. Although phosphorylation of PRAS40 at threonine 246 by Akt is primarily involved in inhibiting cellular apoptosis and increasing survival, the role of unphosphorylated PRAS40 in the cancer cells needs further investigation.

Another well-known substrate of Akt is GSK3 [6, 117], which is present in cells as two structurally similar GSK3 $\alpha$ and GSK $3 \beta$ isoforms [168]. Akt has been shown to phosphorylate S9 of GSK3 $\beta$ and S21 of GSK3 $\alpha$ to inhibit their activity thereby promoting cell proliferation by stabilizing cyclin-D1 protein [29, 117]. Therefore, unphosphorylated active GSK3 is considered as an apoptosis inducing tumor suppressor. However, recent studies have shown that GSK3 expression is elevated in advanced cancers and deregulation of GSK3 activity increases malignant transformation of cells [168-171]. Recently it has been observed that inhibition of GSK3 $\beta$ enhances sorafenib-induced apoptosis in melanoma cells [172]. Furthermore, targeting GSK3 $\beta$ using organometallic inhibitors (DW1/2) decreased Mdm2 activity thereby elevating p53-mediated apoptosis in melanoma cell lines expressing wild-type p53 protein [173]. Finally, GSK $3 \alpha$ and not GSK $3 \beta$ has been shown to regulate pancreatic cell survival [174]. However, similar studies have not been reported in melanomas. Therefore, identifying the actual isoform regulating melanoma development by selectively inhibiting these isoforms using siRNA is warranted. Furthermore, studies are also warranted to demonstrate which isoform is expressed in melanoma patient tumors in order to establish its clinical relevance.

\section{Clinical Implications of Targeting the PI3k-Akt3 Signaling Cascade in Melanomas}

Targeting PI3K-Akt3 signaling has significant clinical potential for inhibiting melanoma tumor development [23]. For example, introduction of PTEN into melanoma cells or inhibiting Akt3 using siRNA or small molecule inhibitors such as ISC-4 inhibited melanoma tumors growth in vitro and in animals $[175,176]$. Furthermore, expression of PTEN or reduction of Akt3 activity has been found to increase melanoma cell sensitivity to apoptotic stimuli that occurs with most chemotherapeutic agents $[9,21,176]$. 
4.1. PTEN Reexpression Prevents Melanoma Development. Tumor suppressor PTEN has been demonstrated to inhibit melanoma development in cultured cells and in spontaneous melanoma models $[9,21,47]$. For example, introduction of PTEN into advanced-stage melanoma cells via a chromosomal transfer or ectopic expression using a plasmidbased vector inhibited tumor development in xenografted melanoma models $[8,15,177]$. Thus, targeted delivery of PTEN into melanoma cells has potential to be an effective therapeutic agent. Restoration of functional PTEN in these cells would increase the therapeutic efficacy of antimelanoma agents $[8,9,21]$. For example, isogenic cell lines expressing PTEN containing low pAkt are sensitive to staurosporineinduced apoptotic cell death, whereas cell lines that lost PTEN are resistant to therapeutic agents [8, 9, 21] (Figures 1 and 2). Furthermore, if PTEN expression was regulated by endogenous microRNAs, inhibiting using antimers could significantly upregulate PTEN activity thereby restoring the chemosensitivity of the melanoma cells. However, PTEN regulation by microRNAs has not yet been reported in melanomas.

\subsection{Therapeutic Agents Targeting PI3K and Akt3 Signaling} Cascades in Melanoma. Targeting Akt3 alone or in combination inhibits growth by inducing apoptosis, decreasing survival, and inhibiting proliferation of melanoma cells $[5,9,21]$. Several synthetic and naturally occurring small molecule inhibitors specifically inhibiting Akt activity have been developed and efficacy tested for inhibiting melanoma development in cultured cells and xenografted animal models $[6,9,21,46,122,151,176,178]$. For example, isoselenocyanate ISC-4 has been demonstrated to inhibit early melanocytic lesions and advanced xenografted melanoma tumors in animals [122]. Compared to known inhibitors of Akt signaling such as API-2, the selenium containing ISC-4 appears to be more effective for melanoma treatment [122]. BI-69A11 is another Akt inhibitor, demonstrated to effectively inhibit melanoma tumors [179]. However, clinical utility of these inhibitors for decreasing melanoma development has not been evaluated yet. Similarly, safety and efficacy of other inhibitors of PI3K-Akt signaling such as GSK690693 (developed by GlaxoSmithKline), a novel ATPcompetitive inhibitor of Akt kinases [180] and SR13668 (developed by SRI international), an NCI approved Akt inhibitor [181, 182], also need to be tested in clinic.

Since the efficacy of a particular inhibitor in vitro or in preclinical animal models may not exactly reflect the potency of the compound in clinical trials, testing these new inhibitors in clinic is highly recommended. For example, perifosine, the alkylsphophocholine analogue, is found to be very effective (inhibiting growth of cancer cells at 0.2 to $0.3 \mu \mathrm{M}$ concentration) in vitro and in animal models. However, a Phase-II study using perifosine in 18 previously untreated patients with metastatic melanoma demonstrated no objective response [183].

4.3. Targeting Multiple Pathways to Synergistically Treat Melanoma. Several lines of evidence now suggest that it might be required to target multiple signaling pathways to inhibit melanoma development. For example, a recent study shows that inhibiting ${ }^{\mathrm{V} 600 \mathrm{E}} \mathrm{B}$-Raf using PLX-4720 induced resistance to apoptosis by activating Akt signaling $[48,149]$. Furthermore, it is also now well established that targeting ${ }^{{ }^{6} 600 \mathrm{E}} \mathrm{B}-$ Raf not only induces resistance to various therapeutic agents but also stimulates the activity of C-Raf and wt B-Raf signaling thereby triggering the formation of keratoacanthomas and basal cell carcinomas [7, 184]. Therefore, it is important to target multiple signaling cascades to inhibit melanoma development. However, it is not completely known which targets should be inhibited. Studies have provided some directions in this regard by showing synergistically acting melanoma tumor inhibition by simultaneously targeting PI3K/Akt3 and MAP kinase signaling pathways [32, 46, 151, 185-187]. For example (a) delivering siRNAs inhibiting Akt3 and ${ }^{{ }^{6} 600 \mathrm{E}} \mathrm{B}$-Raf synergistically inhibited melanoma tumor cells growth in culture or in xenografted melanoma tumors [46, 151] (Figures 9 and 10); (b) combining nanoliposomal ceramide with sorafenib synergistically reduced melanoma cell growth [188]; (c) pharmacological agents inhibiting MAPK (U0126, PD98059 and PD325901) and mTORC1 (using rapamycin) more effectively reduced melanoma cells growth compared to either of the agents tested singly [24, 189, 190]; (d) topical application of LY-294002 and U0126 in combination effectively decreased melanoma tumor incidence in the transgenic TPRas mouse model when compared to either of these agents alone [191]; (e) targeting PI3K and mTOR using dual inhibitors NVP-BBD130 and NVP-BEZ235 effectively reduced the size of primary melanoma tumors and inhibited cervical lymph node metastasis in a syngenic mouse melanoma model. Although these studies demonstrate the potential therapeutic efficacy of combined target inhibition, no complete tumor reduction occurred in any of these studies, warranting the identification of other candidates and target combinations for treating this disease.

Other key targets regulating melanoma development have been recently identified. For example, Yang et al. showed the effect conditional ablation of Ikkb on melanoma tumor development using an established HRasV12 mouse model of spontaneous melanoma [192]. Ink4a/Arf ${ }^{-/}$mice with melanocyte-specific deletion of Ikkb were protected from HRasV12-initiated melanoma only when p53 was expressed. Ikkb ablation was found to decrease Aurora-A kinase and IL-6 in melanomas [192]. Therefore Ikkb and Aurora-A could be potential targets in melanomas [192]. However, it is not known whether targeting these pathways would synergize with Akt inhibition. In support of this direction of investigation, a recent study reported that Aurora-A regulates cancer cell survival by inducing Akt activity and inhibiting Aurora kinase with VX-680 synergizes with pharmacological inhibition of Akt (wortmannin) activity [193]. However, experimental evidence pertaining to which Aurora kinase isoform needs to be targeted for the greater synergistic effect is currently unknown.

It is fairly certain that both MAP and PI3 kinase pathways will need to be targeted for inhibiting melanoma. For 
UACC 903

(effect of cotargeting Akt3 and ${ }^{\mathrm{V} 600 \mathrm{E}} \mathrm{B}-\mathrm{Raf}$

on anchorage independent growth)

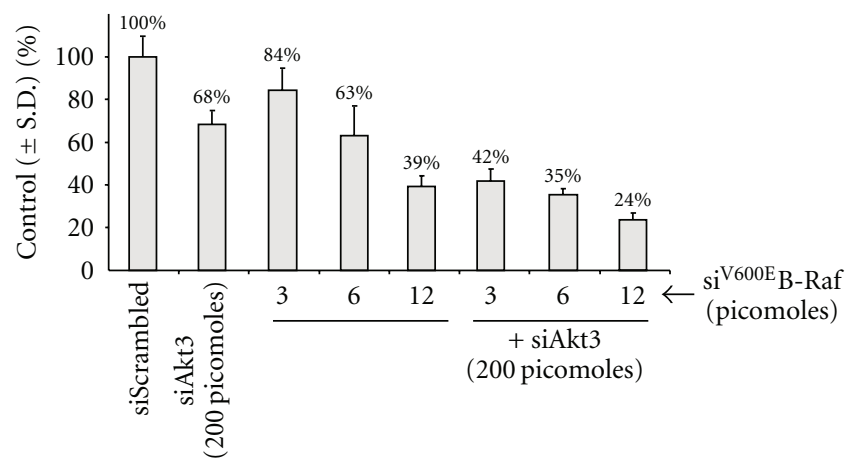

FIgURE 9: Cotargeting Akt3 and ${ }^{\mathrm{V} 600 \mathrm{E}} \mathrm{B}-$ Raf inhibits melanoma cell proliferation in vitro. Two hundred picomoles of siRNA targeting Akt3 and increasing (3, 6, and 12 picomoles) amounts of siRNA inhibiting ${ }^{\mathrm{V} 600 \mathrm{E}} \mathrm{B}$-Raf were introduced alone or in combination into UACC 903 melanoma cell line by Amaxa transfection and effect on anchorage independent growth ability measured using MTS assay. The data shows a dose-dependent inhibition of cell viability when Akt3 and ${ }^{\mathrm{V} 600 \mathrm{E}} \mathrm{B}$-Raf were inhibited. However, maximal effect was observed only when Akt3 and ${ }^{\mathrm{V}}{ }^{600 \mathrm{E}} \mathrm{B}$-Raf targeted together, indicating the necessity of inhibiting multiple signaling cascades $[46,151]$.

example, hybrid compounds that inhibit these pathways such as HMBA (hexamethylene bisacetamide-HMBA), which simultaneously inhibits Akt and MAPK pathways and represses $\mathrm{NF} \kappa \mathrm{B}$ activity in breast cancer cell lines, needs to be tested in melanomas [194]. Similarly, recent studies have demonstrated the utility of a novel selenium containing iNOS inhibitor, called PBISe, for inhibiting melanoma cell growth in vitro and in vivo [195]. Intraperitoneally administered or topically applied PBISe inhibited iNOS and PI3K/Akt3 signaling thereby inducing significant apoptosis in melanoma cells. Furthermore, PBISe-mediated inhibition of Akt3 signaling induced cell senescence by upregulating pErk1/2 to inhibitory levels which triggered the induction of cell cycle inhibitors p21, p16, and p27 [196, 197]. Inhibitors targeting PI3K also have potential to inhibit melanoma growth [67]. For example, SF1126, a conjugate of LY294002 and a pan-PI3K inhibitor, developed by Semafore Pharmaceuticals, is currently in Phase-I clinical trial for solid tumors [198]. Other PI3K inhibitors that are under clinical investigation include GDC-0941, an inhibitor of p110 $\alpha$ subunit developed by Genentech, Inc; and XL-147 and XL-765, developed by Exelixis [198]. However, it is not known whether these inhibitors could synergistically inhibit melanoma development when combined with agents inhibiting other key signaling cascades.

\section{Conclusions}

Activation of Akt3 is a key event regulating the development of melanomas. Enzymes involved in this signaling pathway regulate cell survival, proliferation, metastasis and are implicated in development of resistance to a variety

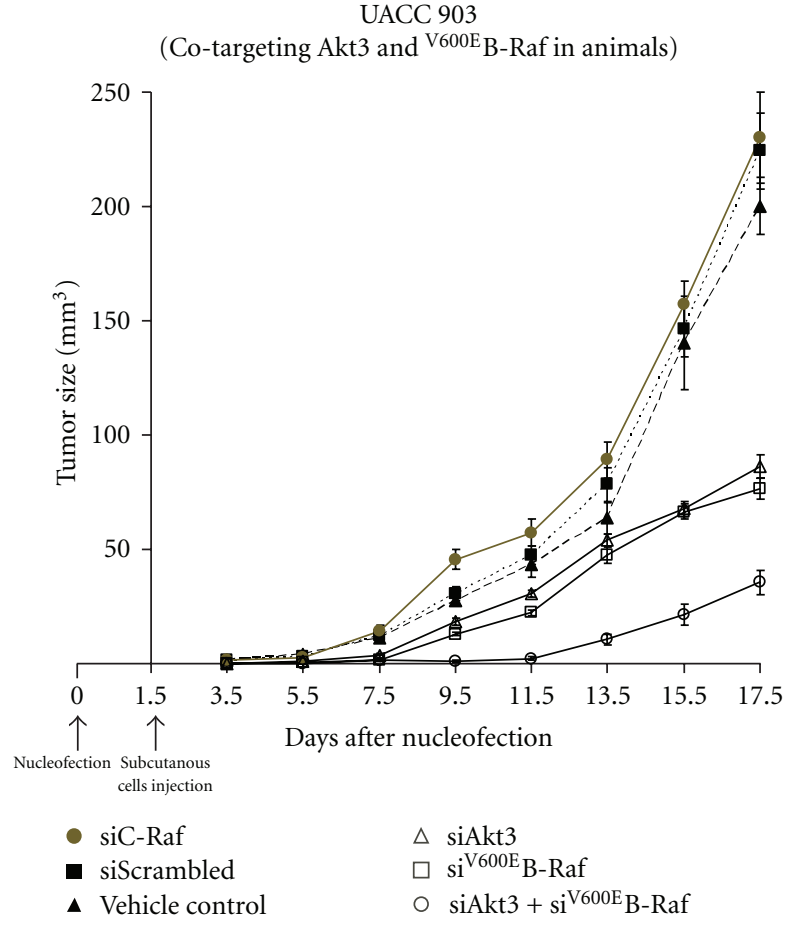

Figure 10: Akt3 synergizes with ${ }^{\mathrm{V} 600 \mathrm{E}} \mathrm{B}$-Raf in melanomas. UACC 903 cells transfected with siRNA targeting Akt3 and ${ }^{\mathrm{V} 600 \mathrm{E}} \mathrm{B}-\mathrm{Raf}$ alone and in combination were subcutaneously injected into mice and effect on tumor development measured. Cotargeting these two key kinases inhibited melanoma development more effectively than inhibiting each of these kinases alone $[46,151]$.

of chemotherapeutic agents. Mechanisms regulating Akt3 phosphorylation such as loss of PTEN, and activation of PI3K signaling need to be further unraveled to aid in the design of novel therapeutic strategies for treating melanoma. Therefore, PI3K-Akt3 signaling remains an attractive target in melanomas. Although this review provides an overview of the PI3K-Akt signaling in melanomas, several aspects need further investigation. Several unanswered questions also remain pertaining to this key signaling cascade. For example, it is not known (a) which microRNAs are regulating Akt signaling in melanomas, (b) whether endogenous Akt 3 is also regulating metastasis development in human melanomas, and (c) how Akt2 is regulating melanoma metastasis and whether targeting Akt2 alone could inhibit metastasis development? Addressing these questions might provide a better understanding of the role of Akt signaling in melanoma and help design more potent selective agents for targeting this disease.

\section{Acknowledgment}

Grant support from NIH CA-127892-01A, the Foreman Foundation for Melanoma Research (GPR), Melanoma Research Foundation (SVM) and the American Cancer Society are gratefully Acknowledged. 


\section{References}

[1] T. D. Bunney and M. Katan, "Phosphoinositide signalling in cancer: beyond PI3K and PTEN," Nature Reviews Cancer, vol. 10, no. 5, pp. 342-352, 2010.

[2] A. Carnero, "The PKB/AKT pathway in cancer," Current Pharmaceutical Design, vol. 16, no. 1, pp. 34-44, 2010.

[3] J. S. Lazo and P. Wipf, "Phosphatases as targets for cancer treatment," Current Opinion in Investigational Drugs, vol. 10, no. 12, pp. 1297-1304, 2009.

[4] S. V. Madhunapantula and G. P. Robertson, "Is B-Raf a good therapeutic target for melanoma and other malignancies?" Cancer Research, vol. 68, no. 1, pp. 5-8, 2008.

[5] S. V. Madhunapantula and G. P. Robertson, "The PTENAKT3 signaling cascade as a therapeutic target in melanoma," Pigment Cell and Melanoma Research, vol. 22, no. 4, pp. 400419, 2009.

[6] G. P. Robertson, "Functional and therapeutic significance of Akt deregulation in malignant melanoma," Cancer and Metastasis Reviews, vol. 24, no. 2, pp. 273-285, 2005.

[7] G. S. Inamdar, S. V. Madhunapantula, and G. P. Robertson, "Targeting the MAPK pathway in melanoma: why some approaches succeed and other fail," Biochemical Pharmacology, vol. 80, no. 5, pp. 624-637, 2010.

[8] J. M. Stahl, M. Cheung, A. Sharma, N. R. Trivedi, S. Shanmugam, and G. P. Robertson, "Loss of PTEN promotes tumor development in malignant melanoma," Cancer Research, vol. 63, no. 11, pp. 2881-2890, 2003.

[9] J. M. Stahl, A. Sharma, M. Cheung et al., "Deregulated Akt3 activity promotes development of malignant melanoma," Cancer Research, vol. 64, no. 19, pp. 7002-7010, 2004.

[10] B. D. Manning and L. C. Cantley, "AKT/PKB signaling: navigating downstream," Cell, vol. 129, no. 7, pp. 1261-1274, 2007.

[11] K. S. M. Smalley and M. Herlyn, "Targeting intracellular signaling pathways as a novel strategy in melanoma therapeutics," Annals of the New York Academy of Sciences, vol. 1059, pp. 16-25, 2005.

[12] M. Y. Hsu, F. Meier, and M. Herlyn, "Melanoma development and progression: a conspiracy between tumor and host," Differentiation, vol. 70, no. 9-10, pp. 522-536, 2002.

[13] Y. Chudnovsky, P. A. Khavari, and A. E. Adams, "Melanoma genetics and the development of rational therapeutics," Journal of Clinical Investigation, vol. 115, no. 4, pp. 813-824, 2005.

[14] H. Wu, V. Goel, and F. G. Haluska, "PTEN signaling pathways in melanoma," Oncogene, vol. 22, no. 20, pp. 3113-3122, 2003.

[15] G. P. Robertson, F. B. Furnari, M. E. Miele et al., "In vitro loss of heterozygosity targets the PTEN/MMAC1 gene in melanoma," Proceedings of the National Academy of Sciences of the United States of America, vol. 95, no. 16, pp. 9418-9423, 1998.

[16] J. O. Lee, H. Yang, M. M. Georgescu et al., "Crystal structure of the PTEN tumor suppressor: implications for its phosphoinositide phosphatase activity and membrane association," Cell, vol. 99, no. 3, pp. 323-334, 1999.

[17] T. Maehama and J. E. Dixon, "PTEN: a tumour suppressor that functions as a phospholipid phosphatase," Trends in Cell Biology, vol. 9, no. 4, pp. 125-128, 1999.

[18] K. A. Waite and C. Eng, "Protean PTEN: form and function," American Journal of Human Genetics, vol. 70, no. 4, pp. 829844, 2002.
[19] A. Gericke, M. Munson, and A. H. Ross, "Regulation of the PTEN phosphatase," Gene, vol. 374, no. 1-2, pp. 1-9, 2006.

[20] M. Mikhail, E. Velazquez, R. Shapiro et al., "PTEN expression in melanoma: relationship with patient survival, Bcl-2 expression, and proliferation," Clinical Cancer Research, vol. 11, no. 14, pp. 5153-5157, 2005.

[21] S. V. Madhunapantula, A. Sharma, and G. P. Robertson, "PRAS40 deregulates apoptosis in malignant melanoma," Cancer Research, vol. 67, no. 8, pp. 3626-3636, 2007.

[22] A. L. Stewart, A. M. Mhashilkar, X. H. Yang et al., "PI3K blockade by Ad-PTEN inhibits invasion and induces apoptosis in radial growth phase and metastatic melanoma cells," Molecular Medicine, vol. 8, no. 8, pp. 451-461, 2002.

[23] J. M. Stahl, A. Sharma, M. Cheung et al., "Deregulated Akt3 activity promotes development of malignant melanoma," Cancer Research, vol. 64, no. 19, pp. 7002-7010, 2004.

[24] D. Dankort, D. P. Curley, R. A. Cartlidge et al., "BrafV cooperates with Pten loss to induce metastatic melanoma," Nature Genetics, vol. 41, no. 5, pp. 544-552, 2009.

[25] C. Nogueira, K.-H. Kim, H. Sung et al., "Cooperative interactions of PTEN deficiency and RAS activation in melanoma metastasis," Oncogene, vol. 29, no. 47, pp. 62226232, 2010.

[26] Z. Mounir, J. L. Krishnamoorthy, G. P. Robertson et al., "Tumor suppression by PTENR equires the activation of the PKR-eIF $2 \alpha$ phosphorylation pathway," Science Signaling, vol. 2, no. 102, p. ra85, 2009.

[27] L. C. Cantley and B. G. Neel, "New insights into tumor suppression: PTEN suppresses tumor formation by restraining the phosphoinositide 3-kinase/AKT pathway," Proceedings of the National Academy of Sciences of the United States of America, vol. 96, no. 8, pp. 4240-4245, 1999.

[28] LI. Li and A. H. Ross, "Why is PTEN an important tumor suppressor?" Journal of Cellular Biochemistry, vol. 102, no. 6, pp. 1368-1374, 2007.

[29] S. Ramaswamy, N. Nakamura, F. Vazquez et al., "Regulation of $\mathrm{G}$ progression by the PTEN tumor suppressor protein is linked to inhibition of the phosphatidylinositol 3-kinase/akt pathway," Proceedings of the National Academy of Sciences of the United States of America, vol. 96, no. 5, pp. 2110-2115, 1999.

[30] W. Huang, H. Y. Chang, T. Fei, H. Wu, and Y. G. Chen, "GSK3 $\beta$ mediates suppression of cyclin D2 expression by tumor suppressor PTEN," Oncogene, vol. 26, no. 17, pp. 2471-2482, 2007.

[31] A. Mirmohammadsadegh, A. Marini, S. Nambiar et al., "Epigenetic silencing of the PTEN gene in melanoma," Cancer Research, vol. 66, no. 13, pp. 6546-6552, 2006.

[32] P. Lopez-Bergami, B. Fitchman, and Z. Ronai, "Understanding signaling cascades in melanoma," Photochemistry and Photobiology, vol. 84, no. 2, pp. 289-306, 2008.

[33] T. Tamguney and D. Stokoe, "New insights into PTEN," Journal of Cell Science, vol. 120, no. 23, pp. 4071-4079, 2007.

[34] S. J. Miller, D. Y. Lou, D. C. Seldin, W. S. Lane, and B. G. Neel, "Direct identification of PTEN phosphorylation sites," FEBS Letters, vol. 528, no. 1-3, pp. 145-153, 2002.

[35] Y. Ueda, Y. Su, and A. Richmond, "CCAAT displacement protein regulates nuclear factor-kappa beta-mediated chemokine transcription in melanoma cells," Melanoma Research, vol. 17, no. 2, pp. 91-103, 2007.

[36] P. L. M. Dahia, "PTEN, a unique tumor suppressor gene," Endocrine-Related Cancer, vol. 7, no. 2, pp. 115-129, 2000.

[37] T. Maehama, F. Okahara, and Y. Kanaho, "The tumour suppressor PTEN: involvement of a tumour suppressor 
candidate protein in PTEN turnover," Biochemical Society Transactions, vol. 32, no. 2, pp. 343-347, 2004.

[38] S. S. Kim, N. J. Yoo, E. G. Jeong, M. S. Kim, and S. H. Lee, "Expression of NEDD-1, a PTEN regulator, in gastric and colorectal carcinomas," APMIS, vol. 116, no. 9, pp. 779-784, 2008.

[39] X. Wang, L. C. Trotman, T. Koppie et al., "NEDD4-1 is a proto-oncogenic ubiquitin ligase for PTEN," Cell, vol. 128, no. 1, pp. 129-139, 2007.

[40] H. Tsao, X. Zhang, E. Benoit, and F. G. Haluska, "Identification of PTEN/MMAC1 alterations in uncultured melanomas and melanoma cell lines," Oncogene, vol. 16, no. 26, pp. 3397 3402, 1998.

[41] Y. Yin and W. H. Shen, "PTEN: a new guardian of the genome," Oncogene, vol. 27, no. 41, pp. 5443-5453, 2008.

[42] A. H. Parmiter, G. Balaban, W. H. Clark, and P. C. Nowell, "Possible involvement of the chromosome region 10q24 $\rightarrow$ q26 in early stages of melanocytic neoplasia," Cancer Genetics and Cytogenetics, vol. 30, no. 2, pp. 313-317, 1988.

[43] F. H. Thompson, J. Emerson, S. Olson et al., "Cytogenetics of 158 patients with regional or disseminated melanoma: subset analysis of near-diploid and simple karyotypes," Cancer Genetics and Cytogenetics, vol. 83, no. 2, pp. 93-104, 1995.

[44] F. Mertens, B. Johansson, M. Höglund, and F. Mitelman, "Chromosomal imbalance maps of malignant solid tumors: a cytogenetic survey of 3185 neoplasms," Cancer Research, vol. 57, no. 13, pp. 2765-2780, 1997.

[45] B. C. Bastian, P. E. LeBoit, H. Hamm, E. B. Bröcker, and D. Pinkel, "Chromosomal gains and losses in primary cutaneous melanomas detected by comparative genomic hybridization," Cancer Research, vol. 58, no. 10, pp. 2170-2175, 1998.

[46] M. Cheung, A. Sharma, S. V. Madhunapantula, and G. P. Robertson, "Akt3 and mutant B-Raf cooperate to promote early melanoma development," Cancer Research, vol. 68, no. 9, pp. 3429-3439, 2008.

[47] D. Dankort, D. P. Curley, R. A. Cartlidge et al., "BrafV cooperates with Pten loss to induce metastatic melanoma," Nature Genetics, vol. 41, no. 5, pp. 544-552, 2009.

[48] Y. Shao and A. E. Aplin, "Akt3-mediated resistance to apoptosis in B-RAF-targeted melanoma cells," Cancer Research, vol. 70, no. 16, pp. 6670-6681, 2010.

[49] Y. Wang, J. J. DiGiovanna, J. B. Stern et al., "Evidence of ultraviolet type mutations in xeroderma pigmentosum melanomas," Proceedings of the National Academy of Sciences of the United States of America, vol. 106, no. 15, pp. 62796284, 2009.

[50] J. F. Costello, M. C. Frühwald, D. J. Smiraglia et al., "Aberrant CpG-island methylation has non-random and tumour-typespecific patterns," Nature Genetics, vol. 24, no. 2, pp. 132-138, 2000.

[51] J. Furuta, Y. Umebayashi, K. Miyamoto et al., "Promoter methylation profiling of 30 genes in human malignant melanoma," Cancer Science, vol. 95, no. 12, pp. 962-968, 2004.

[52] H. Tsao, X. Zhang, E. Benoit, and F. G. Haluska, "Identification of PTEN/MMAC1 alterations in uncultured melanomas and melanoma cell lines," Oncogene, vol. 16, no. 26, pp. 33973402, 1998.

[53] P. Guldberg, P. Thor Straten, A. Birck, V. Ahrenkiel, A. F. Kirkin, and J. Zeuthen, "Disruption of the MMAC1/PTEN gene by deletion or mutation is a frequent event in malignant melanoma," Cancer Research, vol. 57, no. 17, pp. 3660-3663, 1997.
[54] R. Böni, A. O. Vortmeyer, G. Burg, G. Hofbauer, and Z. Zhuang, "The PTEN tumour suppressor gene and malignant melanoma," Melanoma Research, vol. 8, no. 4, pp. 300-302, 1998.

[55] J. T. Celebi, I. Shendrik, D. N. Silvers, and M. Peacocke, "Identification of PTEN mutations in metastatic melanoma specimens," Journal of Medical Genetics, vol. 37, no. 9, pp. 653-657, 2000.

[56] A. Birck, V. Ahrenkiel, J. Zeuthen, K. Hou-Jensen, and P. Guldberg, "Mutation and allelic loss of the PTEN/MMAC1 gene in primary and metastatic melanoma biopsies," Journal of Investigative Dermatology, vol. 114, no. 2, pp. 277-280, 2000 .

[57] J. Reifenberger, M. Wolter, J. Boström et al., "Allelic losses on chromosome arm 10q and mutation of the PTEN (MMAC1) tumour suppressor gene in primary and metastatic malignant melanomas," Virchows Archiv, vol. 436, no. 5, pp. 487493, 2000.

[58] M. Poetsch, T. Dittberner, and C. Woenckhaus, "PTEN/ MMAC1 in malignant melanoma and its importance for tumor progression," Cancer Genetics and Cytogenetics, vol. 125, no. 1, pp. 21-26, 2001.

[59] G. P. Robertson, F. B. Furnari, M. E. Miele et al., "In vitro loss of heterozygosity targets the PTEN/MMAC1 gene in melanoma," Proceedings of the National Academy of Sciences of the United States of America, vol. 95, no. 16, pp. 9418-9423, 1998.

[60] H. Tsao, X. Zhang, K. Fowlkes, and F. G. Haluska, "Relative reciprocity of NRAS and PTEN/MMAC1 alterations in cutaneous melanoma cell lines," Cancer Research, vol. 60, no. 7, pp. 1800-1804, 2000.

[61] V. F. Bonazzi, D. Irwin, and N. K. Hayward, "Identification of candidate tumor suppressor genes inactivated by promoter methylation in melanoma," Genes Chromosomes and Cancer, vol. 48, no. 1, pp. 10-21, 2009.

[62] S. Liu, S. Ren, P. Howell, O. Fodstad, and A. I. Riker, "Identification of novel epigenetically modified genes in human melanoma via promoter methylation gene profiling," Pigment Cell and Melanoma Research, vol. 21, no. 5, pp. 545558, 2008.

[63] X. P. Zhou, O. Gimm, H. Hampel, T. Niemann, M. J. Walker, and C. Eng, "Epigenetic PTEN silencing in malignant melanomas without PTEN mutation," American Journal of Pathology, vol. 157, no. 4, pp. 1123-1128, 2000.

[64] P. M. Pollock and J. M. Trent, "The genetics of cutaneous melanoma," Clinics in Laboratory Medicine, vol. 20, no. 4, pp. 667-690, 2000.

[65] T. Saida, "Recent advances in melanoma research," Journal of Dermatological Science, vol. 26, no. 1, pp. 1-13, 2001.

[66] T. F. Franke, "PI3K/Akt: getting it right matters," Oncogene, vol. 27, no. 50, pp. 6473-6488, 2008.

[67] S. A. Aziz, M. Davies, E. Pick et al., "Phosphatidylinositol-3kinase as a therapeutic target in melanoma," Clinical Cancer Research, vol. 15, no. 9, pp. 3029-3036, 2009.

[68] R. Marone, V. Cmiljanovic, B. Giese, and M. P. Wymann, "Targeting phosphoinositide 3-kinase-moving towards therapy," Biochimica et Biophysica Acta, vol. 1784, no. 1, pp. 159-185, 2008.

[69] P. Blume-Jensen and T. Hunter, "Oncogenic kinase signalling," Nature, vol. 411, no. 6835, pp. 355-365, 2001.

[70] J. R. Testa and A. Bellacosa, "AKT plays a central role in tumorigenesis," Proceedings of the National Academy of Sciences of the United States of America, vol. 98, no. 20, pp. 10983-10985, 2001. 
[71] K. M. Nicholson and N. G. Anderson, "The protein kinase B/Akt signalling pathway in human malignancy," Cellular Signalling, vol. 14, no. 5, pp. 381-395, 2002.

[72] P. Rodriguez-Viciana, P. H. Warne, A. Khwaja et al., "Role of phosphoinositide 3-OH kinase in cell transformation and control of the actin cytoskeleton by Ras," Cell, vol. 89, no. 3, pp. 457-467, 1997.

[73] A. Kauffmann-Zeh, P. Rodriguez-Viciana, E. Ulrich et al., "Suppression of c-Myc-induced apoptosis by Ras signalling through PI(3)K and PKB," Nature, vol. 385, no. 6616, pp. 544-548, 1997.

[74] D. Polsky and C. Cordon-Cardo, "Oncogenes in melanoma," Oncogene, vol. 22, no. 20, pp. 3087-3091, 2003.

[75] L. Shayesteh, Y. Lu, W. L. Kuo et al., "PlK3CA is implicated as an oncogene in ovarian cancer," Nature Genetics, vol. 21, no. 1, pp. 99-102, 1999.

[76] Y. Y. Ma, S. J. Wei, Y. C. Lin et al., "PIK3CA as an oncogene in cervical cancer," Oncogene, vol. 19, pp. 2739-2744, 2000.

[77] S. Tachiiri, K. Sasai, N. Oya, and M. Hiraoka, "Enhanced cell killing by overexpression of dominant-negative phosphatidylinositol 3-kinase subunit, $\Delta \mathrm{p} 85$, following genotoxic stresses," Japanese Journal of Cancer Research, vol. 91, no. 12, pp. 1314-1318, 2000.

[78] D. P. Brazil, J. Park, and B. A. Hemmings, "PKB binding proteins: getting in on the Akt," Cell, vol. 111, no. 3, pp. 293303, 2002.

[79] M. P. Scheid and J. R. Woodgett, "PKB/AKT: functional insights from genetic models," Nature Reviews Molecular Cell Biology, vol. 2, no. 10, pp. 760-768, 2001.

[80] M. P. Scheid and J. R. Woodgett, "Unravelling the activation mechanisms of protein kinase B/Akt," FEBS Letters, vol. 546, no. 1, pp. 108-112, 2003.

[81] A. Bellacosa, J. R. Testa, R. Moore, and L. Larue, "A portrait of AKT kinases: human cancer and animal models depict a family with strong individualities," Cancer Biology and Therapy, vol. 3, no. 3, pp. 268-275, 2004.

[82] D. P. Brazil, Z. Z. Yang, and B. A. Hemmings, "Advances in protein kinase B signalling: AKTion on multiple fronts," Trends in Biochemical Sciences, vol. 29, no. 5, pp. 233-242, 2004.

[83] D. P. Brazil and B. A. Hemmings, "Ten years of protein kinase B signalling: a hard Akt to follow," Trends in Biochemical Sciences, vol. 26, no. 11, pp. 657-664, 2001.

[84] S. R. Datta, A. Brunet, and M. E. Greenberg, "Cellular survival: a play in three akts," Genes and Development, vol. 13, no. 22, pp. 2905-2927, 1999.

[85] S. E. Lietzke, S. Bose, T. Cronin et al., "Structural basis of 3-phosphoinositide recognition by Pleckstrin homology domains," Molecular Cell, vol. 6, no. 2, pp. 385-394, 2000.

[86] K. M. Ferguson, J. M. Kavran, V. G. Sankaran et al., "Structural basis for discrimination of 3-phosphoinositides by pleckstrin homology domains," Molecular Cell, vol. 6, no. 2, pp. 373-384, 2000.

[87] P. F. Jones, T. Jakubowicz, and B. A. Hemmings, "Molecular cloning of a second form of rac protein kinase," Cell Regulation, vol. 2, no. 12, pp. 1001-1009, 1991.

[88] M. Andjelkovic, P. F. Jones, U. Grossniklaus et al., "Developmental regulation of expression and activity of multiple forms of the Drosophila RAC protein kinase," Journal of Biological Chemistry, vol. 270, no. 8, pp. 4066-4075, 1995.

[89] D. R. Alessi, M. Andjelkovic, B. Caudwell et al., "Mechanism of activation of protein kinase B by insulin and IGF-1," EMBO Journal, vol. 15, no. 23, pp. 6541-6551, 1996.
[90] H. Konishi, S. Kuroda, M. Tanaka et al., "Molecular cloning and characterization of a new member of the RAC protein kinase family: association of the pleckstrin homology domain of three types of RAC protein kinase with protein kinase $\mathrm{C}$ subspecies and $\beta \gamma$ subunits of $\mathrm{G}$ proteins," Biochemical and Biophysical Research Communications, vol. 216, no. 2, pp. 526-534, 1995.

[91] D. Brodbeck, M. M. Hill, and B. A. Hemmings, "Two splice variants of protein kinase $\mathrm{B} \gamma$ have different regulatory capacity depending on the presence or absence of the regulatory phosphorylation site serine 472 in the carboxyl-terminal hydrophobic domain," Journal of Biological Chemistry, vol. 276, no. 31, pp. 29550-29558, 2001.

[92] Y. Liao and M. C. Hung, "Physiological regulation of Akt activity and stability," American Journal of Translational Research, vol. 2, no. 1, pp. 19-42, 2010.

[93] E. Gonzalez and T. E. McGraw, "The Akt kinases: isoform specificity in metabolism and cancer," Cell Cycle, vol. 8, no. 16, pp. 2502-2508, 2009.

[94] W. S. Chen, P. Z. Xu, K. Gottlob et al., "Growth retardation and increased apoptosis in mice with homozygous disruption of the akt1 gene," Genes and Development, vol. 15, no. 17, pp. 2203-2208, 2001.

[95] R. S. Garofalo, S. J. Orena, K. Rafidi et al., "Severe diabetes, age-dependent loss of adipose tissue, and mild growth deficiency in mice lacking Akt2/PKB $\beta$," Journal of Clinical Investigation, vol. 112, no. 2, pp. 197-208, 2003.

[96] O. Tschopp, Z. Z. Yang, D. Brodbeck et al., "Essential role of protein kinase $\mathrm{B} \gamma(\mathrm{PKB} \gamma / \mathrm{Akt} 3)$ in postnatal brain developmental but not in glucose homeostasis," Development, vol. 132, no. 13, pp. 2943-2954, 2005.

[97] E. Gonzalez and T. E. McGraw, "Insulin-modulated Akt subcellular localization determines Akt isoform-specific signaling," Proceedings of the National Academy of Sciences of the United States of America, vol. 106, no. 17, pp. 7004-7009, 2009.

[98] R. L. Dillon, R. Marcotte, B. T. Hennessy, J. R. Woodgett, G. B. Mills, and W. J. Muller, "Akt1 and Akt2 play distinct roles in the initiation and metastatic phases of mammary tumor progression," Cancer Research, vol. 69, no. 12, pp. 5057-5064, 2009.

[99] J. Brugge, M. C. Hung, and G. B. Mills, "A new mutational aktivation in the PI3K pathway," Cancer Cell, vol. 12, no. 2, pp. 104-107, 2007.

[100] W. L. Yang, C. Y. Wu, J. Wu, and H. K. Lin, "Regulation of Akt signaling activation by ubiquitination," Cell Cycle, vol. 9, no. 3, pp. 486-497, 2010.

[101] B. T. Hennessy, D. L. Smith, P. T. Ram, Y. Lu, and G. B. Mills, "Exploiting the PI3K/AKT pathway for cancer drug discovery," Nature Reviews Drug Discovery, vol. 4, no. 12, pp. 988-1004, 2005.

[102] B. Vanhaesebroeck and D. R. Alessi, "The PI3K-PBK1 connection: more than just a road to PKB," Biochemical Journal, vol. 346, no. 3, pp. 561-576, 2000.

[103] J. Huang and B. D. Manning, "A complex interplay between Akt, TSC2 and the two mTOR complexes," Biochemical Society Transactions, vol. 37, no. 1, pp. 217-222, 2009.

[104] M. E. Feldman, B. Apsel, A. Uotila et al., "Active-site inhibitors of mTOR target rapamycin-resistant outputs of mTORC1 and mTORC2," PLoS Biology, vol. 7, no. 2, article e38, 2009.

[105] S. Andrabi, O. V. Gjoerup, J. A. Kean, T. M. Roberts, and B. Schaffhausen, "Protein phosphatase $2 \mathrm{~A}$ regulates life and 
death decisions via Akt in a context-dependent manner," Proceedings of the National Academy of Sciences of the United States of America, vol. 104, no. 48, pp. 19011-19016, 2007.

[106] T. Gao, F. Furnari, and A. C. Newton, "PHLPP: a phosphatase that directly dephosphorylates Akt, promotes apoptosis, and suppresses tumor growth," Molecular Cell, vol. 18, no. 1, pp. 13-24, 2005.

[107] L. C. Trotman, A. Alimonti, P. P. Scaglioni, J. A. Koutcher, C. Cordon-Cardo, and P. P. Pandolfi, "Identification of a tumour suppressor network opposing nuclear Akt function," Nature, vol. 441, no. 7092, pp. 523-527, 2006.

[108] P. P. Ruvolo, "Ceramide regulates cellular homeostasis via diverse stress signaling pathways," Leukemia, vol. 15, no. 8, pp. 1153-1160, 2001.

[109] W. L. Yang, J. Wang, C. H. Chan et al., "The E3 Ligase TRAF6 regulates akt ubiquitination and activation," Science, vol. 325, no. 5944, pp. 1134-1138, 2009.

[110] J. D. Carpten, A. L. Faber, C. Horn et al., "A transforming mutation in the pleckstrin homology domain of AKT1 in cancer," Nature, vol. 448, no. 7152, pp. 439-444, 2007.

[111] M. A. Davies, K. Stemke-Hale, C. Tellez et al., "A novel AKT3 mutation in melanoma tumours and cell lines," British Journal of Cancer, vol. 99, no. 8, pp. 1265-1268, 2008.

[112] J. M. Askham, F. Platt, P. A. Chambers, H. Snowden, C. F. Taylor, and M. A. Knowles, "AKT1 mutations in bladder cancer: identification of a novel oncogenic mutation that can co-operate with E17K," Oncogene, vol. 29, no. 1, pp. 150-155, 2010.

[113] M. S. Kim, E. G. Jeong, N. J. Yoo, and S. H. Lee, "Mutational analysis of oncogenic AKT E17K mutation in common solid cancers and acute leukaemias," British Journal of Cancer, vol. 98, no. 9, pp. 1533-1535, 2008.

[114] H. Do, B. Solomon, P. L. Mitchell, S. B. Fox, and A. Dobrovic, "Detection of the transforming AKT1 mutation E17K in non-small cell lung cancer by high resolution melting," BMC Research Notes, vol. 1, article 14, 2008.

[115] P. Dhawan, A. B. Singh, D. L. Ellis, and A. Richmond, "Constitutive activation of Akt/protein kinase B in melanoma leads to up-regulation of nuclear factor- $\kappa \mathrm{B}$ and tumor progression," Cancer Research, vol. 62, no. 24, pp. 7335-7342, 2002.

[116] J. R. Woodgett, "Recent advances in the protein kinase B signaling pathway," Current Opinion in Cell Biology, vol. 17, no. 2, pp. 150-157, 2005.

[117] J. Á. Fresno Vara, E. Casado, J. de Castro, P. Cejas, C. Belda-Iniesta, and M. González-Barón, "P13K/Akt signalling pathway and cancer," Cancer Treatment Reviews, vol. 30, no. 2, pp. 193-204, 2004.

[118] K. S. Kovacina, G. Y. Park, S. S. Bae et al., "Identification of a proline-rich Akt substrate as a 14-3-3 binding partner," Journal of Biological Chemistry, vol. 278, no. 12, pp. 1018910194, 2003.

[119] L. Wang, T. E. Harris, R. A. Roth, and J. C. Lawrence Jr., "PRAS40 regulates mTORC1 kinase activity by functioning as a direct inhibitor of substrate binding," Journal of Biological Chemistry, vol. 282, no. 27, pp. 20036-20044, 2007.

[120] T. Ikenoue, F. Kanai, Y. Hikiba et al., "Functional consequences of mutations in a putative Akt phosphorylation motif of B-raf in human cancers," Molecular Carcinogenesis, vol. 43, no. 1, pp. 59-63, 2005.

[121] L. Packer, S. Pavey, A. Parker et al., "Osteopontin is a downstream effector of the PI3-kinase pathway in melanomas that is inversely correlated with functional PTEN," Carcinogenesis, vol. 27, no. 9, pp. 1778-1786, 2006.
[122] A. Sharma, A. K. Sharma, S. V. Madhunapantula et al., "Targeting Akt3 signaling in malignant melanoma using isoselenocyanates," Clinical Cancer Research, vol. 15, no. 5, pp. 1674-1685, 2009.

[123] M. A. Davies, K. Stemke-Hale, E. Lin et al., "Integrated molecular and clinical analysis of AKT activation in metastatic melanoma," Clinical Cancer Research, vol. 15, no. 24, pp. 7538-7546, 2009.

[124] J. Laine, G. Künstle, T. Obata, MA. Sha, and M. Noguchi, "The protooncogene TCL1 is an Akt kinase coactivator," Molecular Cell, vol. 6, no. 2, pp. 395-407, 2000.

[125] J. Laine, G. Künstle, T. Obata, and M. Noguchi, "Differential regulation of Akt kinase isoforms by the members of the TCL1 oncogene family," Journal of Biological Chemistry, vol. 277, no. 5, pp. 3743-3751, 2002.

[126] Y. Pekarsky, A. Koval, C. Hallas et al., "Tcl1 enhances Akt kinase activity and mediates its nuclear translocation," Proceedings of the National Academy of Sciences of the United States of America, vol. 97, no. 7, pp. 3028-3033, 2000.

[127] H. A. Walz, X. Shi, MY. Chouinard et al., "Isoformspecific regulation of akt signaling by the endosomal protein WDFY2," Journal of Biological Chemistry, vol. 285, no. 19, pp. 14101-14108, 2010.

[128] A. Schenck, L. Goto-Silva, C. Collinet et al., "The endosomal protein Appll mediates Akt substrate specificity and cell survival in vertebrate development," Cell, vol. 133, no. 3, pp. 486-497, 2008.

[129] S. S. Shin, B. A. Wall, J. S. Goydos, and S. Chen, "AKT2 is a downstream target of metabotropic glutamate receptor 1 (Grm1)," Pigment Cell and Melanoma Research, vol. 23, no. 1, pp. 103-111, 2010.

[130] S. P. Staal, "Molecular cloning of the akt oncogene and its human homologues AKT1 and AKT2: amplification of AKT1 in a primary human gastric adenocarcinoma," Proceedings of the National Academy of Sciences of the United States of America, vol. 84, no. 14, pp. 5034-5037, 1987.

[131] J. Q. Cheng, A. K. Godwin, A. Bellacosa et al., "AKT2, a putative oncogene encoding a member of a subfamily of protein-serine/threonine kinases, is amplified in human ovarian carcinomas," Proceedings of the National Academy of Sciences of the United States of America, vol. 89, no. 19, pp. 9267-9271, 1992.

[132] J. Q. Cheng, B. Ruggeri, W. M. Klein et al., "Amplification of AKT2 in human pancreatic cancer cells and inhibition of AKT2 expression and tumorigenicity by antisense RNA," Proceedings of the National Academy of Sciences of the United States of America, vol. 93, no. 8, pp. 3636-3641, 1996.

[133] Y. Lu, Z. Li, and M. Sun, "Multiple gene alterations involved in the processor of human gastric carcinogenesis," Chinese Medical Journal, vol. 75, no. 11, pp. 679-682, 1995.

[134] A. Bellacosa, D. De Feo, A. K. Godwin et al., "Molecular alterations of the AKT2 oncogene in ovarian and breast carcinomas," International Journal of Cancer, vol. 64, no. 4, pp. 280-285, 1995.

[135] H. Van Dekken, E. Geelen, W. N. M. Dinjens et al., "Comparative genomic hybridization of cancer of the gastroesophageal junction: deletion of 14Q31-32.1 discriminates between esophageal (Barrett's) and gastric cardia adenocarcinomas," Cancer Research, vol. 59, no. 3, pp. 748-752, 1999.

[136] A. Bellacosa, D. De Feo, A. K. Godwin et al., "Molecular alterations of the AKT2 oncogene in ovarian and breast carcinomas," International Journal of Cancer, vol. 64, no. 4, pp. 280-285, 1995. 
[137] J. Q. Cheng, B. Ruggeri, W. M. Klein et al., "Amplification of AKT2 in human pancreatic cancer cells and inhibition of AKT2 expression and tumorigenicity by antisense RNA," Proceedings of the National Academy of Sciences of the United States of America, vol. 93, no. 8, pp. 3636-3641, 1996.

[138] F. H. Thompson, M. A. Nelson, J. M. Trent et al., "Amplification of 19q13.1-q13.2 sequences in ovarian cancer: Gband, FISH, and molecular studies," Cancer Genetics and Cytogenetics, vol. 87, no. 1, pp. 55-62, 1996.

[139] V. Waldmann, J. Wacker, and M. Deichmann, "Mutations of the activation-associated phosphorylation sites at codons 308 and 473 of protein kinase B are absent in human melanoma," Archives of Dermatological Research, vol. 293, no. 7, pp. 368$372,2001$.

[140] V. Waldmann, J. Wacker, and M. Deichmann, "Absence of mutations in the pleckstrin homology $(\mathrm{PH})$ domain of protein kinase B (PKB/Akt) in malignant melanoma," Melanoma Research, vol. 12, no. 1, pp. 45-50, 2002.

[141] M. Andjelković, T. Jakubowicz, P. Cron, X. F. Ming, J. W. Han, and B. A. Hemmings, "Activation and phosphorylation of a pleckstrin homology domain containing protein kinase (RAC-PK/PKB) promoted by serum and protein phosphatase inhibitors," Proceedings of the National Academy of Sciences of the United States of America, vol. 93, no. 12, pp. 5699-5704, 1996.

[142] S. Sato, N. Fujita, and T. Tsuruo, "Modulation of Akt kinase activity by binding to Hsp90," Proceedings of the National Academy of Sciences of the United States of America, vol. 97, no. 20, pp. 10832-10837, 2000.

[143] N. Fujita, S. Sato, A. Ishida, and T. Tsuruo, "Involvement of Hsp90 in signaling and stability of 3-phosphoinositidedependent kinase-1," Journal of Biological Chemistry, vol. 277, no. 12, pp. 10346-10353, 2002.

[144] R. J. Lin, Y. C. Lin, and A. L. Yu, "miR-149* induces apoptosis by inhibiting Akt1 and E2F1 in human cancer cells," Molecular Carcinogenesis, vol. 49, pp. 719-727, 2010.

[145] A. M. Roccaro, A. Sacco, B. Thompson et al., "MicroRNAs $15 \mathrm{a}$ and 16 regulate tumor proliferation in multiple myeloma," Blood, vol. 113, no. 26, pp. 6669-6680, 2009.

[146] A. Jetzt, J. A. Howe, M. T. Horn et al., "Adenoviral-Mediated Expression of a Kinase-Dead Mutant of Akt Induces Apoptosis Selectively in Tumor Cells and Suppresses Tumor Growth in Mice," Cancer Research, vol. 63, no. 20, pp. 6697-6706, 2003.

[147] B. Govindarajan, J. E. Sligh, B. J. Vincent et al., "Overexpression of Akt converts radial growth melanoma to vertical growth melanoma," Journal of Clinical Investigation, vol. 117, no. 3, pp. 719-729, 2007.

[148] B. Bedogni, J. A. Warneke, B. J. Nickoloff, A. J. Giaccia, and M. B. Powell, "Notch1 is an effector of Akt and hypoxia in melanoma development," Journal of Clinical Investigation, vol. 118, no. 11, pp. 3660-3670, 2008.

[149] J. Tsai, J. T. Lee, W. Wang et al., "Discovery of a selective inhibitor of oncogenic B-Raf kinase with potent antimelanoma activity," Proceedings of the National Academy of Sciences of the United States of America, vol. 105, no. 8, pp. 3041-3046, 2008.

[150] C. C. Jiang, D. Wroblewski, F. Yang, P. Hersey, and D. Z. $\mathrm{Xu}$, "Human melanoma cells under endoplasmic reticulum stress are more susceptible to apoptosis induced by the $\mathrm{BH} 3$ mimetic obatoclax," Neoplasia, vol. 11, no. 9, pp. 945-955, 2009.

[151] M. A. Tran, R. Gowda, A. Sharma et al., "Targeting BRaf and Akt3 using nanoliposomal-small interfering RNA inhibits cutaneous melanocytic lesion development," Cancer Research, vol. 68, no. 18, pp. 7638-7649, 2008.

[152] D. L. Dai, M. Martinka, and G. Li, "Prognostic significance of activated Akt expression in melanoma: a clinicopathologic study of 292 cases," Journal of Clinical Oncology, vol. 23, no. 7, pp. 1473-1482, 2005.

[153] K. Jiang, J. Sun, J. Cheng, J. Y. Djeu, S. Wei, and S. Sebti, "Akt mediates Ras downregulation of RhoB, a suppressor of transformation, invasion, and metastasis," Molecular and Cellular Biology, vol. 24, no. 12, pp. 5565-5576, 2004.

[154] D. R. Alessi, A. Cuenda, P. Cohen, D. T. Dudley, and A. R. Saltiel, "PD 098059 is a specific inhibitor of the activation of mitogen-activated protein kinase kinase in vitro and in vivo," Journal of Biological Chemistry, vol. 270, no. 46, pp. 2748927494, 1995.

[155] T. Obata, M. B. Yaffe, G. G. Leparc et al., "Peptide and protein library screening defines optimal substrate motifs for AKT/PKB," Journal of Biological Chemistry, vol. 275, no. 46, pp. 36108-36115, 2000.

[156] G. Li, K. Satyamoorthy, and M. Herlyn, "N-cadherinmediated intercellular interactions promote survival and migration of melanoma cells," Cancer Research, vol. 61, no. 9, pp. 3819-3825, 2001.

[157] S. S. Kang, T. Kwon, D. Y. Kwon, and S. I. Do, "Akt protein kinase enhances human telomerase activity through phosphorylation of telomerase reverse transcriptase subunit," Journal of Biological Chemistry, vol. 274, no. 19, pp. 1308513090, 1999.

[158] T. Kwon, D. Y. Kwon, J. Chun, J. H. Kim, and S. S. Kang, "Akt protein kinase inhibits Rac1-GTP binding through phosphorylation at serine 71 of Rac1," Journal of Biological Chemistry, vol. 275, no. 1, pp. 423-428, 2000.

[159] N. Wajapeyee, R. W. Serra, X. Zhu, M. Mahalingam, and M. R. Green, "Oncogenic BRAF induces senescence and apoptosis through pathways mediated by the secreted protein IGFBP7," Cell, vol. 132, no. 3, pp. 363-374, 2008.

[160] R. Houben, S. Ortmann, A. Drasche, J. Troppmair, M. J. Herold, and J. C. Becker, "Proliferation arrest in B-Raf mutant melanoma cell lines upon MAPK pathway activation," Journal of Investigative Dermatology, vol. 129, no. 2, pp. 406-414, 2009.

[161] Y. Zhao, Y. Zhang, Z. Yang, A. Li, and J. Dong, "Simultaneous knockdown of BRAF and expression of INK4A in melanoma cells leads to potent growth inhibition and apoptosis," Biochemical and Biophysical Research Communications, vol. 370, no. 3, pp. 509-513, 2008.

[162] V. K. Goel, N. Ibrahim, G. Jiang et al., "Melanocytic nevuslike hyperplasia and melanoma in transgenic BRAFV600E mice," Oncogene, vol. 28, no. 23, pp. 2289-2298, 2009.

[163] A. Saito, P. Narasimhan, T. Hayashi, S. Okuno, M. FerrandDrake, and P. H. Chan, "Neuroprotective role of a prolinerich akt substrate in apoptotic neuronal cell death after stroke: relationships with nerve growth factor," Journal of Neuroscience, vol. 24, no. 7, pp. 1584-1593, 2004.

[164] B. Huang and G. Porter, "Expression of proline-rich Aktsubstrate PRAS40 in cell survival pathway and carcinogenesis," Acta Pharmacologica Sinica, vol. 26, no. 10, pp. 12531258, 2005.

[165] N. Oshiro, R. Takahashi, K. I. Yoshino et al., "The prolinerich Akt substrate of $40 \mathrm{kDa}$ (PRAS40) is a physiological substrate of mammalian target of rapamycin complex 1," Journal of Biological Chemistry, vol. 282, no. 28, pp. 2032920339, 2007. 
[166] Y. Sancak, C. C. Thoreen, T. R. Peterson et al., "PRAS40 is an insulin-regulated inhibitor of the mTORC1 protein kinase," Molecular Cell, vol. 25, no. 6, pp. 903-915, 2007.

[167] E. B. M. Nascimento, M. Snel, B. Guigas et al., "Phosphorylation of PRAS40 on Thr246 by PKB/AKT facilitates efficient phosphorylation of Ser183 by mTORC1," Cellular Signalling, vol. 22, no. 6, pp. 961-967, 2010.

[168] S. Patel and J. Woodgett, "Glycogen synthase kinase-3 and cancer: good cop, bad cop?" Cancer Cell, vol. 14, no. 5, pp. 351-353, 2008.

[169] J. Luo, "Glycogen synthase kinase $3 \beta$ (GSK3 $\beta$ ) in tumorigenesis and cancer chemotherapy," Cancer Letters, vol. 273, no. 2, pp. 194-200, 2009.

[170] B. Bellei, E. Flori, E. Izzo, V. Maresca, and M. Picardo, "GSK3 $\beta$ inhibition promotes melanogenesis in mouse B16 melanoma cells and normal human melanocytes," Cellular Signalling, vol. 20, no. 10, pp. 1750-1761, 2008.

[171] A. V. Ougolkov and D. D. Billadeau, "Targeting GSK-3: a promising approach for cancer therapy?" Future Oncology, vol. 2, no. 1, pp. 91-100, 2006.

[172] D. J. Panka, D. C. Cho, M. B. Atkins, and J. W. Mier, "GSK$3 \beta$ inhibition enhances sorafenib-induced apoptosis in melanoma cell lines," Journal of Biological Chemistry, vol. 283, no. 2, pp. 726-732, 2008.

[173] K. S. M. Smalley, R. Contractor, N. K. Haass et al., "An organometallic protein kinase inhibitor pharmacologically activates p53 and induces apoptosis in human melanoma cells," Cancer Research, vol. 67, no. 1, pp. 209-217, 2007.

[174] W. Wilson 3rd and A. S. Baldwin, "Maintenance of constitutive $\mathrm{I} \kappa \mathrm{B}$ kinase activity by glycogen synthase kinase- $3 \alpha / \beta$ in pancreatic cancer," Cancer Research, vol. 68, no. 19, pp. 81568163, 2008.

[175] R. W. Johnstone, A. A. Ruefli, and S. W. Lowe, "Apoptosis: a link between cancer genetics and chemotherapy," Cell, vol. 108, no. 2, pp. 153-164, 2002.

[176] M. S. Soengas and S. W. Lowe, "Apoptosis and melanoma chemoresistance," Oncogene, vol. 22, no. 20, pp. 3138-3151, 2003.

[177] M. Poetsch, T. Dittberner, and C. Woenckhaus, "PTEN/ MMAC1 in malignant melanoma and its importance for tumor progression," Cancer Genetics and Cytogenetics, vol. 125, no. 1, pp. 21-26, 2001.

[178] A. K. Sharma, A. Sharma, D. Desai et al., "Synthesis and anticancer activity comparison of phenylalkyl isoselenocyanates with corresponding naturally occurring and synthetic isothiocyanates," Journal of Medicinal Chemistry, vol. 51, no. 24, pp. 7820-7826, 2008.

[179] S. Gaitonde, S. K. De, M. Tcherpakov et al., "BI-69A11mediated inhibition of AKT leads to effective regression of xenograft melanoma," Pigment Cell and Melanoma Research, vol. 22, no. 2, pp. 187-195, 2009.

[180] N. Rhodes, D. A. Heerding, D. R. Duckett et al., "Characterization of an Akt kinase inhibitor with potent pharmacodynamic and antitumor activity," Cancer Research, vol. 68, no. 7, pp. 2366-2374, 2008.

[181] I. M. Kapetanovic, M. Muzzio, S. C. Hu et al., "Pharmacokinetics and enhanced bioavailability of candidate cancer preventative agent, SR13668 in dogs and monkeys," Cancer Chemotherapy and Pharmacology, vol. 65, no. 6, pp. 11091116, 2010.

[182] W. R. Chao, D. Yean, K. Amin, C. Green, and L. Jong, "Computer-aided rational drug design: a novel agent (SR13668) designed to mimic the unique anticancer mechanisms of dietary indole-3-carbinol to block Akt signaling,"
Journal of Medicinal Chemistry, vol. 50, no. 15, pp. 34123415, 2007.

[183] D. S. Ernst, E. Eisenhauer, N. Wainman et al., "Phase II study of perifosine in previously untreated patients with metastatic melanoma," Investigational New Drugs, vol. 23, no. 6, pp. 569-575, 2005.

[184] K. H. T. Paraiso, I. V. Fedorenko, L. P. Cantini et al., "Recovery of phospho-ERK activity allows melanoma cells to escape from BRAF inhibitor therapy," British Journal of Cancer, vol. 102, no. 12, pp. 1724-1730, 2010.

[185] K. S. M. Smalley and K. T. Flaherty, "Integrating BRAF/MEK inhibitors into combination therapy for melanoma," British Journal of Cancer, vol. 100, no. 3, pp. 431-435, 2009.

[186] M. Krasilnikov, V. N. Ivanov, J. Dong, and Z. Ronai, "ERK and PI3K negatively regulate STAT-transcriptional activities in human melanoma cells: implications towards sensitization to apoptosis," Oncogene, vol. 22, no. 26, pp. 4092-4101, 2003.

[187] F. Meier, B. Schittek, S. Busch et al., "The Ras/Raf/MEK/ERK and PI3K/AKT signaling pathways present molecular targets for the effective treatment of advanced melanoma," Frontiers in Bioscience, vol. 10, no. 3, pp. 2986-3001, 2005.

[188] M. A. Tran, C. D. Smith, M. Kester, and G. P. Robertson, "Combining nanoliposomal ceramide with sorafenib synergistically inhibits melanoma and breast cancer cell survival to decrease tumor development," Clinical Cancer Research, vol. 14, no. 11, pp. 3571-3581, 2008.

[189] K. G. Lasithiotakis, T. W. Sinnberg, B. Schittek et al., "Combined inhibition of MAPK and mTOR signaling inhibits growth, induces cell death, and abrogates invasive growth of melanoma cells," Journal of Investigative Dermatology, vol. 128, no. 8, pp. 2013-2023, 2008.

[190] J. LoPiccolo, G. M. Blumenthal, W. B. Bernstein, and P. A. Dennis, "Targeting the PI3K/Akt/mTOR pathway: effective combinations and clinical considerations," Drug Resistance Updates, vol. 11, no. 1-2, pp. 32-50, 2008.

[191] B. Bedogni, S. M. Welford, A. C. Kwan, J. Ranger-Moore, K. Saboda, and M. B. Powell, "Inhibition of phosphatidylinositol-3-kinase and mitogen-activated protein kinase kinase 1/2 prevents melanoma development and promotes melanoma regression in the transgenic TPRas mouse model," Molecular Cancer Therapeutics, vol. 5, no. 12, pp. 3071-3077, 2006.

[192] J. Yang, R. Splittgerber, F. E. Yull et al., "Conditional ablation of Ikkb inhibits melanoma tumor development in mice," Journal of Clinical Investigation, vol. 120, no. 7, pp. 25632574, 2010.

[193] J.-E. Yao, M. Yan, Z. Guan et al., "Aurora-A down-regulates IkappaB $\alpha$ via Akt activation and interacts with insulinlike growth factor-1 induced phosphatidylinositol 3-kinase pathway for cancer cell survival," Molecular Cancer, vol. 8, article 95, 2009.

[194] A. Dey, E. Wong, N. Kua, L. T. Hsiang, V. Tergaonkar, and D. Lane, "Hexamethylene bisacetamide (HMBA) simultaneously targets AKT and MAPK pathway and represses $\mathrm{NF} \kappa \mathrm{B}$ activity: implications for cancer therapy," Cell Cycle, vol. 7, no. 23, pp. 3759-3767, 2008.

[195] S. V. Madhunapantula, D. Desai, A. Sharma, J. H. Sung, S. Amin, and G. P. Robertson, "PBISe, a novel seleniumcontaining drug for the treatment of malignant melanoma," Molecular Cancer Therapeutics, vol. 7, no. 5, pp. 1297-1308, 2008.

[196] C. Michaloglou, L. C. W. Vredeveld, W. J. Mooi, and D. S. Peeper, "BRAF in benign and malignant human tumours," Oncogene, vol. 27, no. 7, pp. 877-895, 2008. 
[197] C. Michaloglou, L. C. W. Vredeveld, M. S. Soengas et al., "BRAF-associated senescence-like cell cycle arrest of human naevi," Nature, vol. 436, no. 7051, pp. 720-724, 2005.

[198] J. A. Engelman, "Targeting PI3K signalling in cancer: opportunities, challenges and limitations," Nature Reviews Cancer, vol. 9, no. 8, pp. 550-562, 2009. 

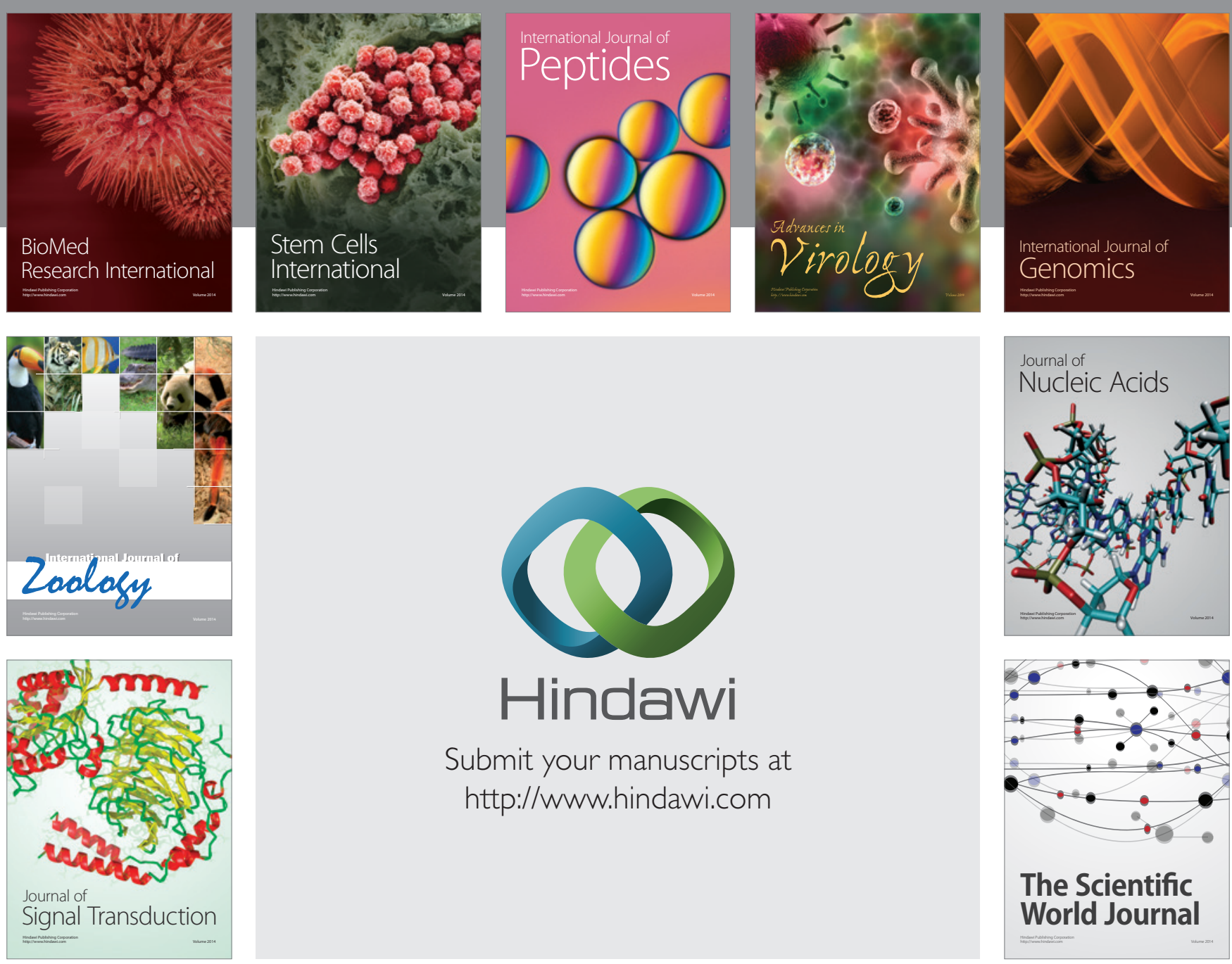

Submit your manuscripts at

http://www.hindawi.com
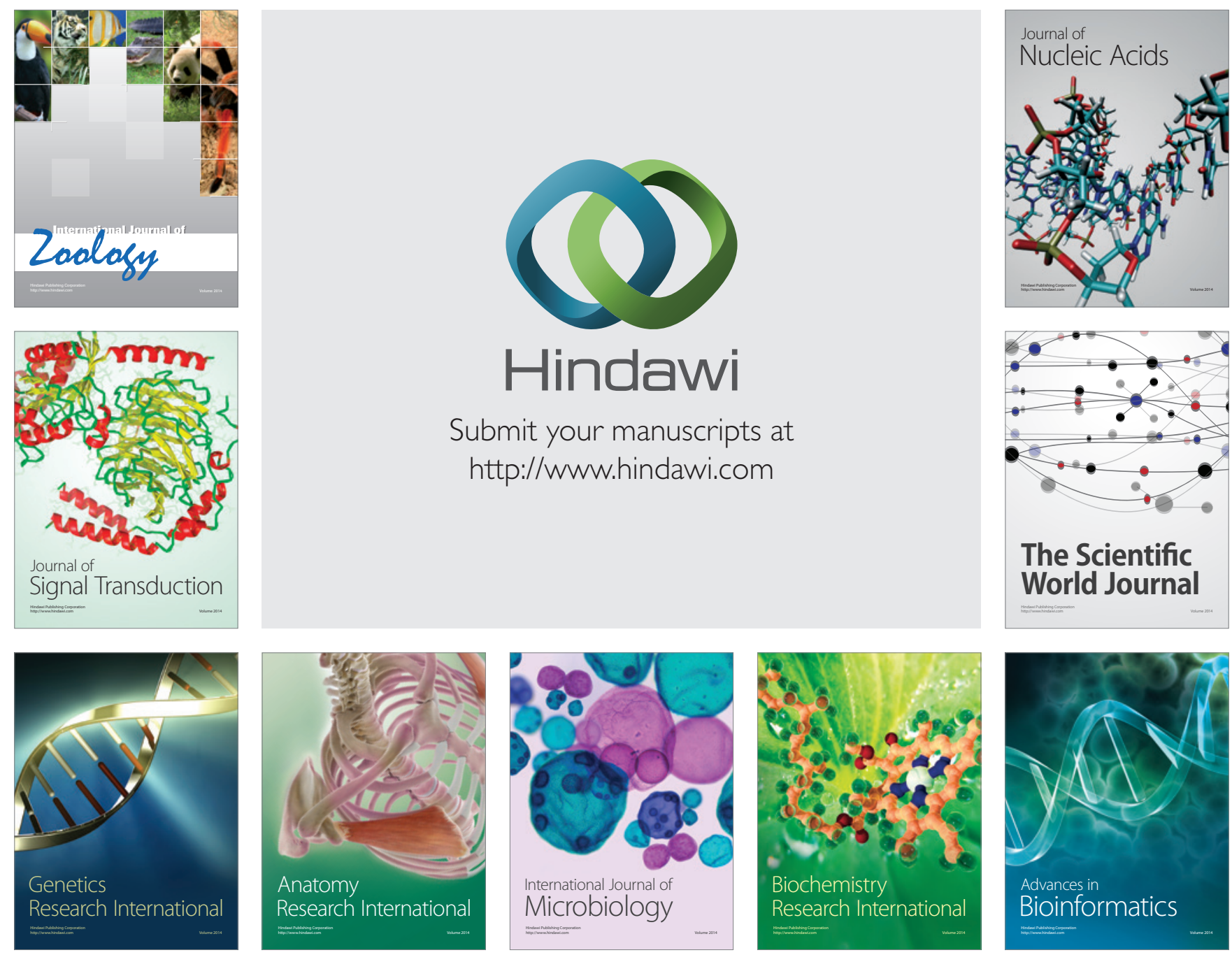

The Scientific World Journal
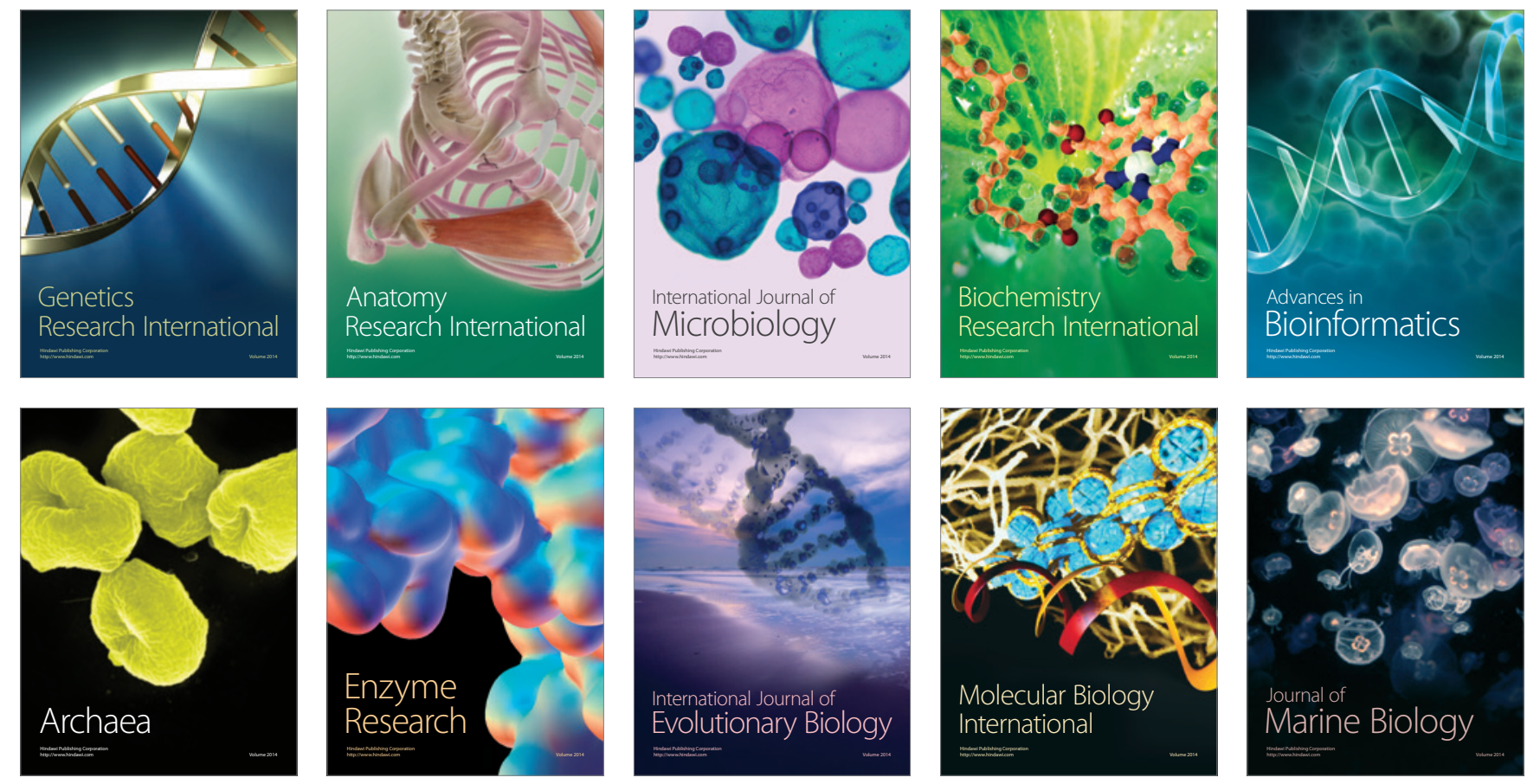